\title{
Endoplasmic Reticulum Stress is Transmissible among Cells of the Central Nervous System
}

\author{
Neil T. Sprenkle
}

Follow this and additional works at: https://researchrepository.wvu.edu/etd

\section{Recommended Citation}

Sprenkle, Neil T., "Endoplasmic Reticulum Stress is Transmissible among Cells of the Central Nervous System" (2017). Graduate Theses, Dissertations, and Problem Reports. 6704.

https://researchrepository.wvu.edu/etd/6704

This Thesis is protected by copyright and/or related rights. It has been brought to you by the The Research Repository @ WVU with permission from the rights-holder(s). You are free to use this Thesis in any way that is permitted by the copyright and related rights legislation that applies to your use. For other uses you must obtain permission from the rights-holder(s) directly, unless additional rights are indicated by a Creative Commons license in the record and/ or on the work itself. This Thesis has been accepted for inclusion in WVU Graduate Theses, Dissertations, and Problem Reports collection by an authorized administrator of The Research Repository @ WVU. For more information, please contact researchrepository@mail.wvu.edu. 


\title{
Endoplasmic Reticulum Stress is Transmissible among Cells of the Central Nervous System
}

\author{
Neil T. Sprenkle \\ Thesis submitted to the faculty of the \\ West Virginia School of Medicine \\ in partial fulfillment of the requirements for the degree of \\ Master of Science \\ In \\ Biomedical Sciences
}

Gordon P. Meares, Ph.D., Chair

Timothy D. Eubank, Ph.D.

David M. Smith, Ph.D.

Morgantown, West Virginia

2017

Keywords:

Cell-nonautonnomous, ER stress, Neurotoxicity, Preconditioning, Stress factor, Stress resistance Copyright 2017 Neil Sprenkle 


\title{
Endoplasmic Reticulum Stress is Transmissible among Cells of the
}

\section{Central Nervous System}

\author{
Neil T. Sprenkle
}

\begin{abstract}
Improper protein folding and trafficking are common pathological events observed in various cell types in neurodegenerative diseases. If the protein quality control mechanisms of the endoplasmic reticulum (ER) fail to re-establish proteostasis, misfolded proteins accumulate within the lumen of the ER and perturb normal cellular processes. While low-level stimulation of the unfolded protein response (UPR) is considered a beneficial physiological response to transient protein misfolding stress, or ER stress, sustained UPR activation resulting from prolonged ER stress can promote neurotoxicity. The cell-autonomous mechanisms of the UPR have been extensively characterized in the context of neuropathology. Nevertheless, there still remain unanswered questions regarding the cell-extrinsic role of the UPR under normal physiology, and how this mechanism is compromised in diseased states. To address this, we evaluated whether transferring conditioned media from ER stressed astrocytes to different cell types could modulate their functional characteristics. Our results indicate that ER stressed astrocytes secrete a mediator(s) which regulates both inflammatory and ER stress responses in other astrocytes and neurons in vitro. Initial exposure to this stress factor(s) confers resistance against subsequent ER stress to neurons by engaging the adaptive signals of the neuronal UPR. However, persistent exposure to this unidentified mediator(s) suppresses the initial protective effect and becomes cytotoxic. Overall, these findings provide insight into the cell-nonautonomous influence of ER stress on cells of the central nervous system. Further understanding the molecular mechanisms
\end{abstract}


underlying this mode of intercellular communication would present novel therapeutic opportunities to treat neurodegenerative disease. 


\section{Dedication}

This thesis is dedicated to my parents, Kamille and Boyd, who have offered unconditional love and support throughout my life. 


\section{Acknowledgements}

First, I would like to thank God for placing me in a situation to succeed, and giving me the strength to persevere through hardship. Next, I would like to thank my research mentor Dr. Gordon Meares for his guidance, encouragement, and patience through my time in the Master's program. Lastly, and just as importantly, I would like to give myself a pat on the back. I worked so hard on this, and I am not afraid to say that without me I would not have been able to do this. 


\section{Table of Contents}

Abstract

Dedication .iv

Acknowledgements ..V

Table of Contents ..vi

List of Symbols, Abbreviations or Nomenclature ..ix

Chapter 1: Introduction

1.1. Motivation 1

1.2. Background 1

1.3. Experimental Hypothesis

1.4. References 4

Chapter 2: Literature Review

2.1. The Physiological Role of the UPR 6

2.2. ER Stress in Neurodegenerative Diseases .20

2.3. References

Chapter 3: Methodology

3.1. Reagents

3.2. Mice and Primary Cell Preparations

3.3. Conditioned Media .50 
3.4. Immunoblot Analysis

3.5. Reverse Transcription-quantitative Polymerase Chain Reaction (qRT-PCR) ......50

3.6. Determining Cell Viability

3.6.1. Caspase-3 Activity Assay

3.6.2. Lactate Dehydrogenase (LDH) Assay

3.6.3. TUNEL Assay

3.7. Microparticle Isolation by Ultracentrifugation .52

3.8. Treatment of Conditioned Media with Proteinase K

3.9. Statistical Analysis

3.10. References .54

Chapter 4: Results

4.1. ER Stress is Transmissible among Cells of the CNS in vitro .55

4.2. ER Stressed Astrocytes Initially Protect Neurons against Subsequent Stress ....56

4.3. The Secreted Stress Factor(s) is not a Microparticle, and is Resistant to Proteinase K .58

4.4. Figure Legend .61

4.5. Figures .65

4.6. References .71

Chapter 5: Discussion 
5.3. Future Direction .76

5.4. Potential Problems and their Solution .76

5.5. References .78 


\section{List of Symbols, Abbreviations or Nomenclature}

A $\beta$ : Amyloid- $\beta$; AD: Alzheimer's disease; ALS: Amyotrophic Lateral Sclerosis; APP: A $\beta$ precursor protien; AP-1: Activator protein 1; ASK1: Apoptosis signal-regulating kinase 1; ATF: Activating transcription factor; BBB: Blood brain barrier; BiP: binding immunoglobulin protein; bZIP: basic leucine zipper; C9orf72: Chromosome 9 open reading frame 72; CHOP: CCAATenhancer-binding protein homologous protein; CNS: Central nervous system; DAMP: dangerassociated molecular patterns; eIF2 $\alpha$ : eukaryotic translation initiation factor $2 \alpha$; ERAD: ERassociated degradation; Ero1 $\alpha$ : ER oxidoreductase $\alpha$; ER: Endoplasmic reticulum; FAD: Familial Alzheimer's disease; FUS: Fused in Sarcoma RNA-binding protein; GADD34: Growth arrest and DNA damage-inducible protein 34; GCN2: General control non-derepressible 2; GRP: Glucoseregulated protein; GSK-3: Glycogen synthase kinase 3; HERV: human endogenous retrovirus; HLA: Human leukocyte antigen; IFN- $\gamma$ : Interferon- $\gamma$; IKK: IкB kinase; IL: Interleukin; IRE-1 $\alpha$; Inositol-requiring enzyme $1 \alpha$; IкB: inhibitors of $\kappa \mathrm{B}$; JAK1: Januse kinase 1 ; JNK: c-Jun Nterminal kinase; Keap1: Kelch-like ECH-associated protein 1; LDH: Lactate dehydrogenase; LRRK2: Leucine-rich repeat kinase 2; MAPK: Mitogen activated protein kinase; MEF: Mouse

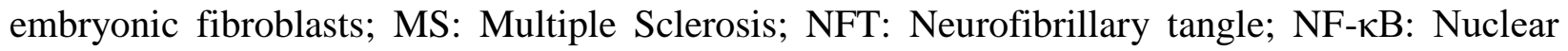
factor kappa-light-chain-enhancer of activated B cells; NOD1/2: Nucleotide-binding oligomerization domain 1/2; Nrf-2: Nuclear factor-like 2; PAMP: pathogen-associated molecular patterns; PDI: Protein disulphide isomerase; PD: Parkinson's disease; PERK: Double-stranded RNA dependent protein kinase-like ER kinase; PKR: double stranded RNA-dependent kinase; PPI: Protein phosphatase 1; PS: Presenilin; RIDD: Regulated IRE1-dependent decay; RIPK2: Receptor-interacting serine/threonine-protein kinase 2; RNase: Endoribonuclease; RNS: Reactive nitrogen species; ROS: Reactive oxygen species; SERCA: sarco/endoplasmic reticulum $\mathrm{Ca}^{2+}$ 
ATPase; SOD1: superoxide dismutase-1; SRP: Signal-recognition particle; STAT: Signal transducers and activators of transcription; sXBP1: Spliced x-box-binding protein 1; TDP43: Transactive response DNA binding protein; TNF- $\alpha$ : Tumor-necrosis factor- $\alpha$; TRAF2: TNF- $\alpha-$ receptor-associated factor 2; TUNEL: Terminal deoxynucleotidyl transferase dUTP nick-end labeling; UPR: Unfolded protein response; WT: Wild-type; XBP1: X-box-binding protein 


\section{Chapter 1: Introduction}

\subsection{Motivation}

Neurological diseases are a devastating public health concern with very few effective treatments and no known cure. Dysfunction in protein homeostasis in brain-resident astrocytes and microglia can promote neuronal death though cell-nonautonomous mechanisms. This project is working to identify novel mechanisms regarding how cellular stress responses encourage a neurotoxic milieu, thereby providing novel targets for therapeutic intervention.

\subsection{Background}

Innate immune activation has emerged as a prominent component in the pathology of many neurodegenerative diseases. Previously, the involvement of immunity in the pathogenesis of neurological disorders had been greatly underappreciated. However, within the last couple decades we have come to realize that an aberrant inflammatory program within the central nervous system (CNS) contributes to neuronal dysfunction [1]. While inflammation is considered a beneficial physiological response, as it promotes debris clearance and aids in tissue repair, sustained inflammatory signaling overwhelms the resolution capabilities of the CNS [2]. This, in turn, is thought to be fundamental to the development of harmful neuroinflammation. Brain-resident microglia and astrocytes are the main source of inflammation in the brain, and under pathological conditions these dysregulated glial cells facilitate the events that promote a neurotoxic microenvironment $[3,4]$. Considering that neurons have a limited regenerative capacity, excessive neuronal loss in the CNS has dire consequences on motor and cognitive function. A wealth of data now supports the hypothesis that inflammation in the CNS may contribute to neurodegeneration 
by establishing a feed-forward inflammatory loop which ultimately leads to sustained neuronal damage $[1,2,5,6]$. Importantly, this likely reflects impairment of the normal mechanisms involved in immune responses in the brain as inflammation, glial activation and even peripheral immune infiltration are essential elements of normal tissue homeostasis and repair [7, 8].

One of the pathological hallmarks of many neurodegenerative diseases is the accumulation of misfolded proteins within the ER of neurons and neuroglia. In response to ER stress, cells induce a highly conserved cellular stress response called the unfolded protein response (UPR) in an attempt to maintain homeostasis [9]. The UPR program orchestrates transcriptional and translational changes in the cell to minimize stress, while concomitantly inducing protein quality control mechanisms in an attempt to reduce protein misfolding. If resolution fails, the temporallyregulated induction of UPR-dependent inflammatory and apoptotic pathways has the potential to exacerbate neuroinflammation and compromise cell fidelity [10-13].

\subsection{Experimental Hypothesis}

It is known that ER stress can be 'transmitted' between distinct cell types and contribute to chronic disease pathology. For instance, ER stressed tumor cells can upregulate canonical ER stress responses in myeloid cells to promote tumor growth and cancer progression through the secretion of an unknown soluble molecule [14]. Interestingly, low-level activation of the UPR plays an essential role in maintaining vital biological processes against up-coming stress by heightening the resolution potential of the ER stress response $[15,16]$. The fact that transmissible ER stress has been observed across different mammalian cell populations suggests that it may be important for conferring cellular protection to surrounding cells in response to various forms of organismal stress $[14,17,18]$. Under diseased states, however, this homeostatic mechanism maybe compromised in order to promote disease progression. 
In this study, we hypothesize that ER stressed astrocytes are able to transmit ER stress to other CNS cell types, and initially confer enhanced resistance to subsequent ER stress. However, prolonged ER dysfunction in receiver cells would upregulate UPR-mediated inflammatory and apoptotic programs that would drive severe inflammatory signaling and promote cell death, respectively. To test this, we incubated multiple cell types with conditioned media from ER stressed astrocytes to determine if they secreted soluble factors that could influence ER stress responses. Here we show that ER stressed astrocyte conditioned media (ACM) upregulates the expression of proteins associated with all three branches of the UPR. Further, IL-6, CCL2 and CCL20 mRNA expression was significantly enhanced in resting astrocytes incubated with ER stressed ACM. Treatment with the chemical chaperone TUDCA partially reduced the expression of these inflammatory mediators, suggesting that both the inflammatory proteins secreted by ER stressed astrocytes and cell-nonautonomous ER stress contribute to inflammatory gene expression. Mild exposure to ER stressed ACM conferred stress resistance to neurons against acute thapsigargin (Thaps)-induced ER stress, as neurons expressed less pro-apoptotic factors and exhibited significantly less caspase-3 activity. Nevertheless, this protective effect was partially lost after prolonged exposure to Thaps. Collectively, these findings will present novel insights into the cell-extrinsic regulatory functions of the UPR. 


\subsection{References}

1. Heneka MT, Kummer MP, Latz E: Innate immune activation in neurodegenerative disease. Nat Rev Immunol 2014, 14(7):463-477.

2. Glass CK, Saijo K, Winner B, Marchetto MC, Gage FH: Mechanisms underlying inflammation in neurodegeneration. Cell 2010, 140(6):918-934.

3. Sofroniew MV: Astrocyte barriers to neurotoxic inflammation. Nat Rev Neurosci 2015, 16(5):249-263.

4. Prinz M, Priller J: Microglia and brain macrophages in the molecular age: from origin to neuropsychiatric disease. Nat Rev Neurosci 2014, 15(5):300-312.

5. Block ML, Hong JS: Microglia and inflammation-mediated neurodegeneration: multiple triggers with a common mechanism. Prog Neurobiol 2005, 76(2):77-98.

6. Perry VH, Nicoll JA, Holmes C: Microglia in neurodegenerative disease. Nat Rev Neurol 2010, 6(4):193-201.

7. DiSabato DJ, Quan N, Godbout JP: Neuroinflammation: the devil is in the details. $J$ Neurochem 2016, 139 Suppl 2:136-153.

8. Lee KM, MacLean AG: New advances on glial activation in health and disease. World $J$ Virol 2015, 4(2):42-55.

9. Hetz C, Mollereau B: Disturbance of endoplasmic reticulum proteostasis in neurodegenerative diseases. Nat Rev Neurosci 2014, 15(4):233-249.

10. Bellezza I, Grottelli S, Mierla AL, Cacciatore I, Fornasari E, Roscini L, Cardinali G, Minelli A: Neuroinflammation and endoplasmic reticulum stress are coregulated by cyclo(His-Pro) to prevent LPS neurotoxicity. Int J Biochem Cell Biol 2014, 51:159-169.

11. Logsdon AF, Lucke-Wold BP, Nguyen L, Matsumoto RR, Turner RC, Rosen CL, Huber JD: Salubrinal reduces oxidative stress, neuroinflammation and impulsive-like behavior in a rodent model of traumatic brain injury. Brain Res 2016, 1643:140-151.

12. Deslauriers AM, Afkhami-Goli A, Paul AM, Bhat RK, Acharjee S, Ellestad KK, Noorbakhsh F, Michalak M, Power C: Neuroinflammation and endoplasmic reticulum stress are coregulated by crocin to prevent demyelination and neurodegeneration. $J$ Immunol 2011, 187(9):4788-4799.

13. Salminen A, Kauppinen A, Suuronen T, Kaarniranta K, Ojala J: ER stress in Alzheimer's disease: a novel neuronal trigger for inflammation and Alzheimer's pathology. $J$ Neuroinflammation 2009, 6:41.

14. Mahadevan NR, Rodvold J, Sepulveda H, Rossi S, Drew AF, Zanetti M: Transmission of endoplasmic reticulum stress and pro-inflammation from tumor cells to myeloid cells. Proc Natl Acad Sci U S A 2011, 108(16):6561-6566.

15. Inagi R, Kumagai $T$, Nishi $H$, Kawakami $T$, Miyata $T$, Fujita $T$, Nangaku M: Preconditioning with endoplasmic reticulum stress ameliorates mesangioproliferative glomerulonephritis. J Am Soc Nephrol 2008, 19(5):915-922.

16. Tsang KY, Chan D, Bateman JF, Cheah KSE: In vivo cellular adaptation to ER stress: survival strategies with double-edged consequences. J Cell Sci 2010, 123(Pt 13):21452154.

17. Zanetti M, Rodvold JJ, Mahadevan NR: The evolving paradigm of cell-nonautonomous UPR-based regulation of immunity by cancer cells. Oncogene 2016, 35(3):269-278. 
18. Zhang H, Yue Y, Sun T, Wu X, Xiong S: Transmissible endoplasmic reticulum stress from myocardiocytes to macrophages is pivotal for the pathogenesis of CVB3-induced viral myocarditis. Sci Rep 2017, 7:42162. 


\section{Chapter 2: Literature Review}

\subsection{The Physiological Role of the UPR}

The majority of proteins destined for the secretory pathway present a hydrophobic Nterminal signal sequence during the initial stages of translation [1, 2]. This amino acid sequence is recognized by the cytosolic protein signal-recognition particle, which coordinates cotranslational translocation of the nascent polypeptide across the ER membrane and into the ER lumen [3, 4]. Here, the unique environment of the ER lumen facilitates the proper folding events that create a stable protein with functional capabilities.

The ER serves as the cell's largest calcium store owing to the consistent active transport of calcium into the lumen [5]. Intraluminal ER calcium is necessary for the activation of calciumdependent molecular chaperones, including the ER resident glucose-regulated proteins (GRPs), which go on to stabilize protein folding intermediates [6]. Furthermore, the ER lumen possesses an oxidative environment which allow protein disulphide isomerases (PDIs) to catalyze the formation of disulfide bonds. Reduced PDIs are reoxidized by endoplasmic reticulum oxidoreductase $\alpha$ (Ero1 $\alpha)$ to allow for continuous oxidation of free cysteine residues residing on unfolded proteins [7]. Additional post-translational modifications, such as glycosylation, are executed within the ER to produce a mature protein that is packaged into coat protein complex IIcoated vesicles and exported out of the ER [8,9]. ER-derived vesicles then enter the canonical secretory pathway where cargo is either targeted to the plasma membrane or to other cellular compartments.

Features of pathophysiological stress in the form of gene mutations, protein aggregates, inflammatory signals, metabolic alterations, pathogen-associated molecular patterns (PAMPs), 
danger-associated molecular pattern molecules (DAMPs) and/or reactive oxygen or nitrogen species (ROS/RNS) disrupts efficient protein folding processes in the ER lumen, thus creating an imbalance between the protein load and the folding capabilities of the ER [10]. The UPR responds to cellular stress by triggering effector mechanisms that can be grouped as adaptive, alarming or pro-apoptotic [6]. In the adaptive phase of the UPR, mammalian cells are able to tolerate moderate protein misfolding by upregulating the expression of chaperone proteins to correctly fold and stabilize the increasing amount of polypeptide transported into the ER lumen. In an effort to maintain quality control, the cell also employs ER-associated degradation (ERAD) and attenuates translation of global messenger RNA (mRNA) to alleviate the protein load within the lumen [11, 12]. In more severe situations, the protein folding capacity of the ER fails to keep pace with the increasing influx of polypeptide, as the extensive accumulation of misfolded proteins in the ER lumen begins to overwhelm the compensatory mechanisms of the UPR. If improperly regulated, the buildup of misfolded proteins will compromise normal cellular processes. Under these conditions, the cell initiates signaling pathways associated with cellular stress, most notably the activation of inflammatory pathways, and 'alarms' the extracellular environment of the distress so that the appropriate tissue-wide response is initiated [6]. If all else fails the UPR will trigger cell death through both caspase-dependent and -independent means [13-15].

\section{Signal Transducers of the ER Stress Response}

In mammalian cells, the central proteins involved in initiating this evolutionarily conserved response are activating transcription factor 6 (ATF6), inositol-requiring $1 \alpha$ (IRE-1 $\alpha$ ) and doublestranded RNA dependent protein kinase-like ER kinase (PERK) [10]. GRP78 (also known as binding immunoglobulin protein (BiP)) primarily regulates the initiation of the UPR through its direct interactions with each signal transducing sensor [16-18] (Figure 1). Physical contact 
between GRP78 and the luminal domain of the ER-transmembrane proteins stabilizes their inactive state. High demand for chaperone-mediated protein stabilization brought on by increases in protein synthesis or defective protein folding recruits GRP78 away from these proteins [17]. Disrupting this interaction frees the luminal domain of the ER sensors, consequently inducing their functional conformation. Recent evidence has suggested an additional regulatory mechanism by which the sensors become catalytically active. By crystallizing the yeast IRE- 1 , Credle et al. elucidated a distinct peptide-binding groove in the IRE-1 luminal domain [19, 20]. In this model, unfolded polypeptide within the ER lumen may act as a substrate for the peptide-binding groove located in IRE-1. Because of the shared structural homology with that of IRE-1, PERK may also be activated in a similar manner [19]. These findings represent a unique sensing mechanism that 
regulates the activation of the UPR.

Interplay between active ATF6, IRE-1 $\alpha$ and PERK initiate signaling cascades that regulate the transcriptional and translational landscape of the cell to selectively promote the expression UPR-target genes. Each of these mediators promote distinct signaling pathways which converge to produce an effective response to mitigate damage. If overwhelmed, these signaling proteins will

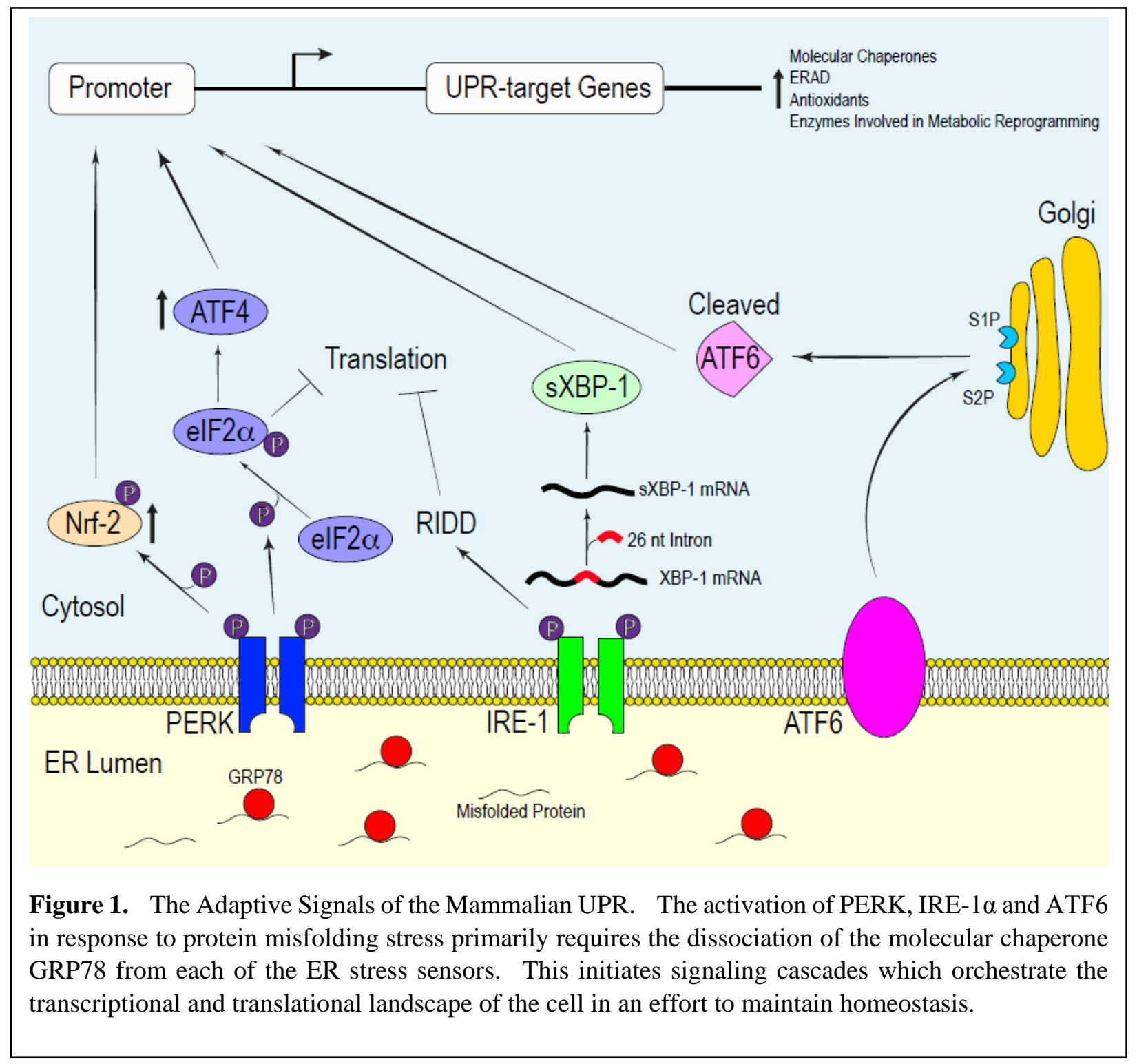

initiate apoptosis [21] (Figure 2). 
Mammalian ATF6 is a type II transmembrane protein embedded within the ER membrane [22]. The carboxyl terminus of ATF6 acts as the intraluminal sensor while the amino terminus protrudes into the cytosol and functions as a basic leucine zipper (bZIP) transcription factor [23]. Dissociation of GRP78 from the luminal domain causes ATF6 to translocate to the Golgi apparatus. Located at the Golgi are site- 1 and site-2 proteases, both of which have been implicated in the regulation of cholesterol metabolism [24]. It is here that ATF6 is cleaved, resulting in the release of the bZIP transcription factor into the cytosol [22]. From the cytosol, the processed ATF6 fragment localizes into the nucleus and helps upregulate the expression of genes responsible for mediating protein folding and ERAD [22, 25].

IRE- $1 \alpha$ is a type 1 transmembrane protein containing an ER-sensing amino terminus, and a cytosolic carboxyl terminal endoribonuclease (RNase) and serine-threonine kinase domain [26, 27]. Detection of unfolded proteins causes IRE-1 $\alpha$ to dimerize and/or form higher order oligomers, which in turn activates its kinase domain. Subsequent trans-autophosphorylation stimulates the RNase activity of IRE-1 $\alpha$ [28]. Acquisition of RNase catalytic activity enables for the excision of a 26-nucleotide intron within a mature X-box-binding protein 1 (XBP1) mRNA transcript in the cytosol [29]. The spliced XBP1 (sXBP1) mRNA encodes for an XBP1 isoform which, like ATF6, binds upstream cis-elements associated with chaperone and ERAD-mediated genes [25, 30]. Sustained ER stress augments the RNase activity of IRE- $1 \alpha$, thereby causing decreased specificity for XBP1 mRNA and elevated degradation of specific classes of mRNAs, 28S ribosomal RNA and microRNAs through regulated IRE1-dependent decay (RIDD) [31]. The degradation of RNA transcripts destined for the ER and ribosomal RNA is thought to initially help diminish mRNA translation to alleviate the protein load on the ER [32]. Nevertheless, prolonged RIDD activity resulting from chronic ER stress contributes to cell death by degrading ER-targeted mRNA that 
encode proteins involved in protein folding and anti-apoptotic microRNA, thus pushing cell fate toward apoptosis [33-35].

Lastly, PERK possesses type 1 transmembrane topology and a cytosolic kinase domain [17]. Structural analysis has revealed that the sensing luminal domain of PERK shares a conserved protein sequence with that of IRE-1 $\alpha$ [12]. Unsurprisingly, both PERK and IRE-1 $\alpha$ respond to ER stress in a similar manner. Along with IRE-1 $\alpha$, PERK indirectly reduces the quantity of unfolded polypeptide within the ER to allow for more efficient chaperone-mediated protein folding in a well-saturated ER lumen. The dimerization of PERK leads to the activation of its cytosolic kinases, which subsequently phosphorylate serine 51 on the $\alpha$-subunit of eukaryotic initiation factor $2 \alpha$ (eIF2 $\alpha$ ) [12]. Phosphorylation of eIF2 $\alpha$ prevents the translation of many nuclear-encoded mRNA transcripts by compromising the formation of the GTP·eIF $2 \alpha \cdot$ Met-tRNA $A_{i}$ ternary complex, which in turn prevents the assembly of the pre-initiation complex at the 5' end of mRNA [36, 37]. Delaying translation re-initiation in this manner increases the probability that ribosomes will scan past inhibitory upstream open reading frames, resulting in increased translation of a specific subset of mRNAs, most notably mRNA that encodes ATF4 [36, 38]. Like ATF6, ATF4 is a bZIP transcription factor important for maintaining intracellular homeostasis through the upregulation of UPR-target genes involved in efficient protein folding, the antioxidant response and amino acid biosynthesis and transport [39]. In addition to promoting an adaptive response, ATF4 regulates the transcription of the gene encoding pro-apoptotic factor CCAAT-enhancer-binding protein homologous protein (CHOP) [40].

While the role of CHOP in stress-induced apoptosis remains obscure, it is thought that CHOP promotes apoptosis by 1) downregulating the expression of Bcl-2, a pro-survival protooncogene, 2) elevating the expression of pro-apoptotic BH3-only Bcl-2 family proteins such as 
Bad, Bim and p53 upregulated modulator of apoptosis and 3) coordinating intracellular calcium signaling [40, 41]. The latter relies on the involvement of the ER. In addition to its role in mediating stable protein folding, the ER serves an important function in cell signaling due to its ability to release calcium in response to second messengers. During unremitting PERK activation, CHOP accumulates to a point necessary to activate Erol $\alpha$, which drives the aperture of the ER calcium release channel inositol 1, 4, 5-triphosphate (IP3) receptor 1 [42, 43]. Prolonged efflux of calcium from the ER promotes the activation of calcium/calmodulin-dependent protein kinase II, which plays a role in promoting cell death [43]. Moreover, free cytosolic calcium leaks into the mitochondrial matrix, causing mitochondrial depolarization [44]. Mitochondrial uptake of calcium released from the ER also elevates the production of ROS through various mechanisms, including activating the mitochondrial permeability transition and stimulating Krebs cycle dehydrogenases $[39,44,45]$. Besides facilitating calcium release, Ero1 $\alpha$ contributes to the production of hydrogen peroxide within the ER lumen [46].

Along with targeting $\mathrm{Bcl}-2$ family genes and Ero1 $\alpha$, CHOP binds to promoter elements associated with growth arrest and DNA damage-inducible protein 34 (GADD34). The induction of GADD34 is imperative for attenuating signals downstream of the PERK-eIF2 $\alpha$-ATF4 pathway. This GADD34-dependent negative feedback loop relies on GADD34 recruiting protein phosphatase 1 (PP1) to dephosphorylate eIF2 $\alpha$. Mutating the conserved motifs important for binding PP1 in GADD34 impairs eIF2 $\alpha$ dephosphorylation, thus supporting its regulatory role in mediating the phosphorylation state of eIF2 $\alpha$ [47]. Moreover, knocking out CHOP diminishes GADD34 protein expression, leading to elevated levels of phosphorylated eIF2 $\alpha$ when compared to wild-type (WT) cells experiencing ER stress [48]. Although GADD34-mediated dephosphorylation of eIF $2 \alpha$ is essential for cells to restore global mRNA translation after acute 
insult, the overexpression of GADD34 increases the translation of mRNA transcripts induced during the later stages of prolonged ER stress, thereby elevating the protein load and restoring global translation of proteins involved in ROS production and apoptosis [49]. Additionally, GADD34 may have pro-apoptotic effects that are independent of its role in regulating eIF2 $\alpha$ phosphorylation that contribute to ER stress-induced cell death [48, 50].

Another downstream effector of active PERK is the bZIP transcription factor nuclear factor-like 2 (Nrf-2), which is important for the expression of antioxidants [51]. Nrf-2 is normally sequestered within the cytosol by kelch-like ECH-associated protein 1 (Keap1) under basal states, however, the initiation of the UPR allows PERK to act on the Nrf-2-Keap1 complex. PERKmediated phosphorylation of Nrf-2 promotes its dissociation from Keap1 and translocation into the nucleus where it upregulates the expression of genes essential for redox homeostasis. Cullinan et al. demonstrated that deleting Nrf-2 compromises the ability of mouse embryonic fibroblasts (MEFs) to cope with ER stress, as cells without Nrf-2 were more susceptible to undergoing ER stress-induced apoptosis compared to WT MEFs treated with tunicamycin, a pharmacological ER stress-inducing agent that blocks $\mathrm{N}$-linked glycosylation [52]. The same study also provided evidence showing that PERK phosphorylation was sufficient to disrupt the Nrf-2-Keap1 complex, thereby allowing Nrf-2 to function as a transcription factor independent of the presence of ROS/RNS. 


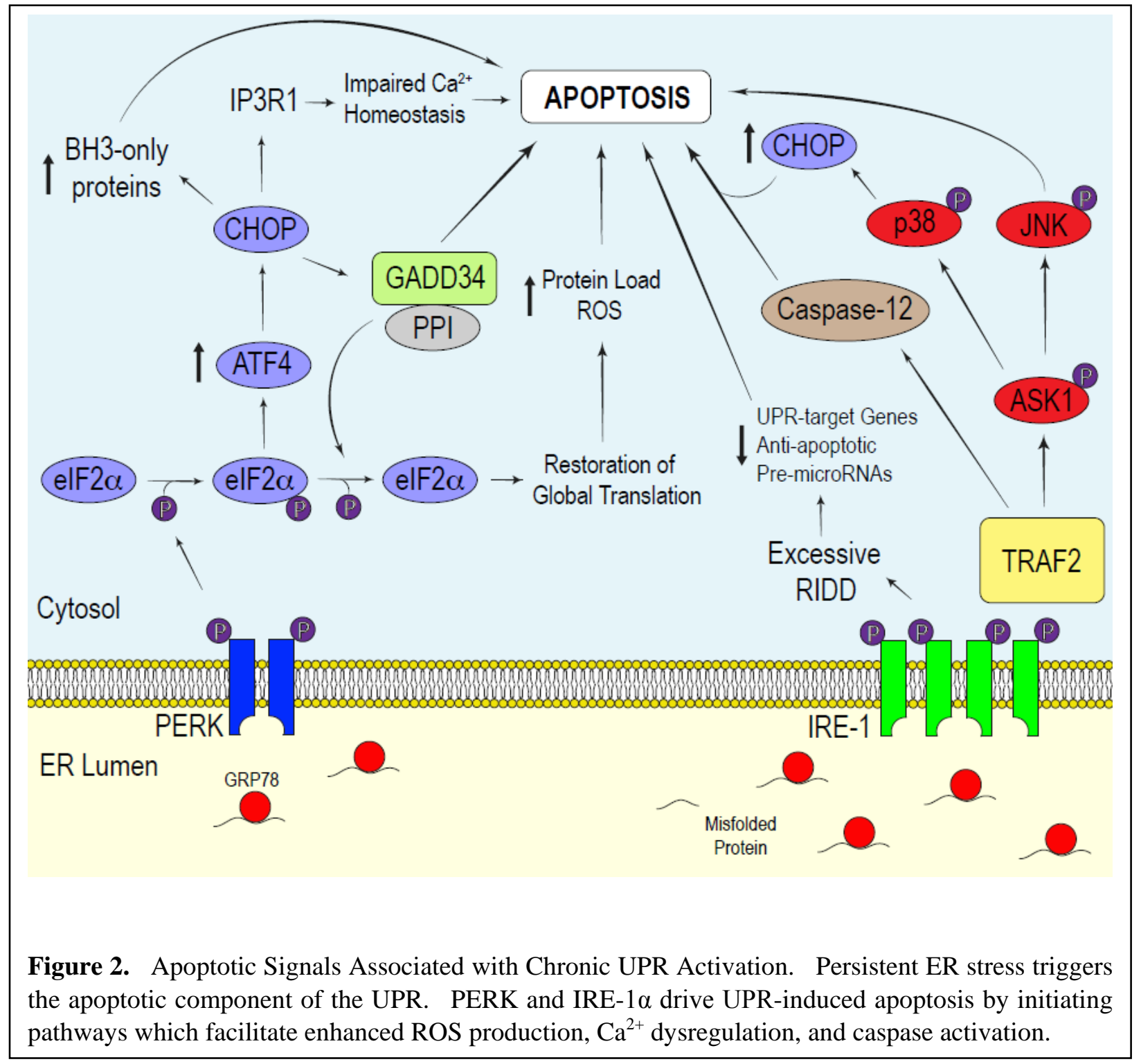

During the UPR, PERK and ATF6 signaling have been shown to upregulate the expression of sXBP1 mRNA (through different mechanisms) to produce an operative transcription factor responsible for inducing the expression of stress-response genes [53, 54]. Furthermore, there is evidence that the transcription of CHOP is also under the control of the active ATF6 transcription factor [55]. This demonstrates that not only do the ER sensors elicit independent signaling cascades 
in the face of ER stress, but there is cross-talk between the different UPR pathways in an effort to provide a robust response to physiological stress. In addition to ATF6 and IRE- $1 \alpha$ regulating the transcription of chaperone proteins and enzymes mediating ERAD, both have also been implicated in the biosynthesis of ER phospholipids, which are used to expand the ER membrane, and in the regulation of other aspects of cellular metabolism [56, 57]. Interestingly, components of the UPR play an essential role in learning, memory and behavior. The eIF2 $\alpha$ kinases, including PERK, regulate memory and synaptic plasticity by modulating gene expression and translation [58]. Moreover, a recent study demonstrated an important role for XBP1 in facilitating memory and long-term potentiation through the regulation of brain-derived neurotrophic factor expression [59]. The involvement of the UPR in optimizing the protein folding capacity of the ER as well as modulating cellular metabolism and cognitive function highlights the pleiotropic actions of the ER stress response in maintaining tissue and organismal homeostasis.

\section{UPR-mediated Inflammatory Pathways}

In addition to coordinating the expression of stress-response genes during ER stress, the UPR initiates inflammatory pathways essential for the innate immune response (Figure 3). The principal inflammatory signaling proteins activated during the UPR are the nuclear factor kappalight-chain-enhancer of activated B cells (NF-kB) and the mitogen activated protein kinase (MAPK) family proteins c-Jun N-terminal kinase (JNK) and p38. It is important to note that NF$\kappa \mathrm{B}$ and the MAPKs regulate not only inflammatory gene expression, but they also play a role in mediating cell survival in a context-specific manner [60]. 


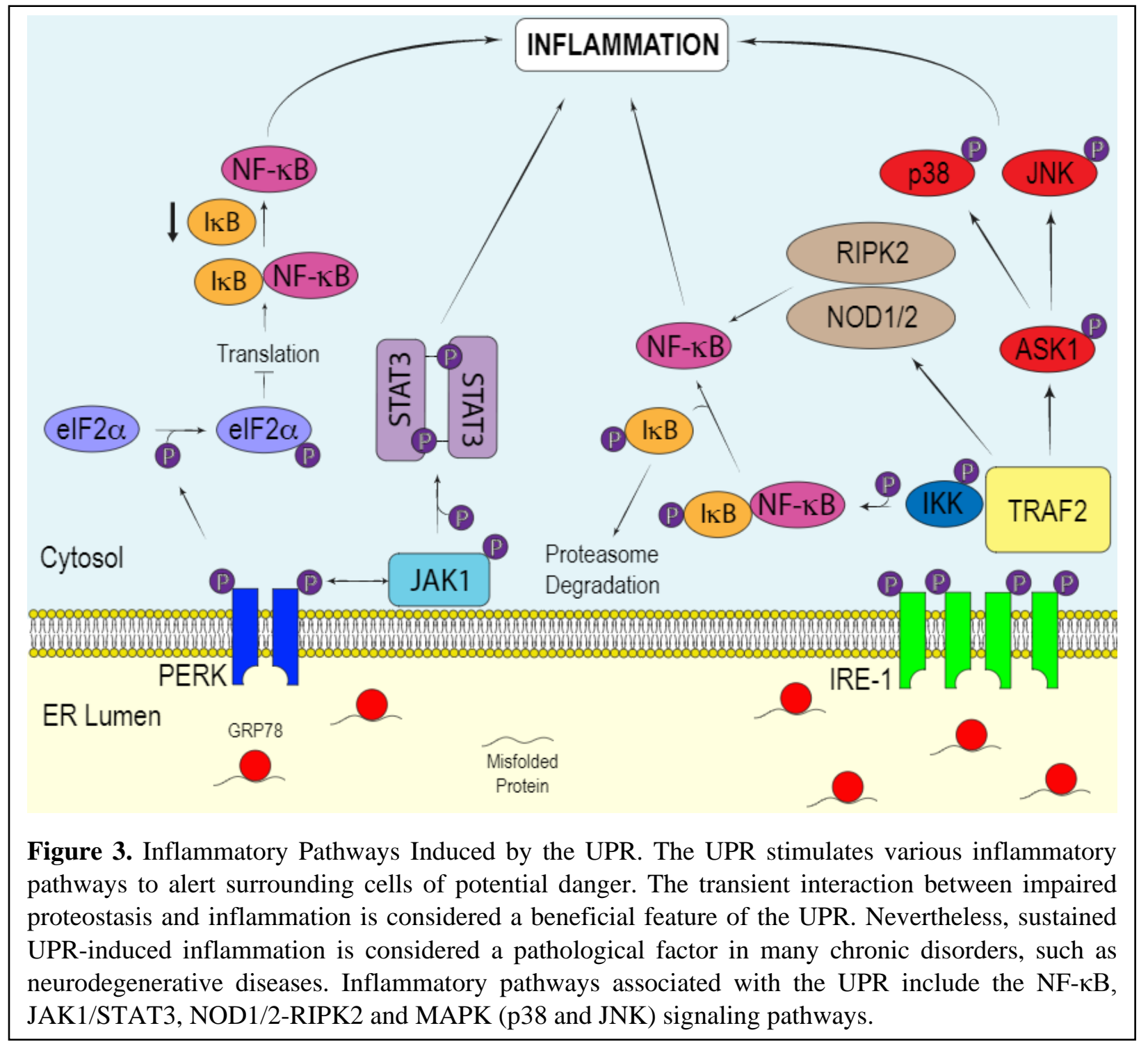

The NF- $\mathrm{B}$ family of proteins are made up of homo- and heterodimeric transcription factors composed of proteins in the NF- $\kappa \mathrm{B} / \mathrm{Rel}$ family [61]. In unstressed cells, NF- $\kappa \mathrm{B}$ is sequestered within the cytosol through physical interaction with inhibitors of $\kappa \mathrm{B}(\mathrm{I} \kappa \mathrm{B})$. Signaling through the canonical NF- $\kappa$ B pathway activates the serine kinase I $\kappa$ B kinase (IKK), which is composed of two catalytic subunits (IKK $\alpha$ and IKK $\beta$ ) and a regulatory subunit (IKK $\gamma$ ). Sitespecific phosphorylation of IкB by IKK signals for its degradation through the ubiquitin-dependent 
recruitment of the $26 \mathrm{~S}$ proteasome [62]. Subsequently, free NF- $\mathrm{BB}$ is able to localize to the nucleus and bind to $\kappa \mathrm{B}$ sites in gene promoters, and drive the expression of cytokines and cell survival proteins. NF- $\mathrm{KB}$ can be activated by various forms of cell stress. For example, in addition to ER stress, elevated levels of cytosolic calcium and oxidative stress have been shown to promote NF$\kappa \mathrm{B}$-mediated transcription $[63,64]$. In the context of ER stress, the attenuation of global mRNA translation in response to eIF $2 \alpha$ phosphorylation provides a means by which NF- $\kappa$ B is stimulated.

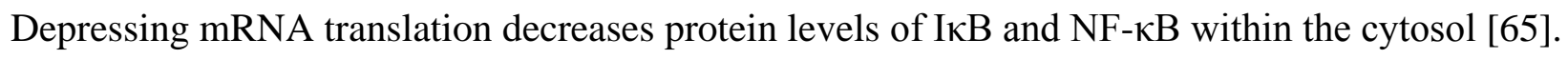
Because I $\kappa$ B has a shorter half-life than NF- $\kappa B$, the higher proportion of NF- $\kappa B$ to I $\kappa$ B favors the migration of free $\mathrm{NF}-\kappa \mathrm{B}$ into the nucleus to upregulate the transcription of inflammatory genes.

Along with PERK, IRE-1 $\alpha$ elicits inflammatory signaling during the ER stress response. After oligomerization, IRE-1 $\alpha$ recruits the adaptor protein tumor-necrosis factor- $\alpha$ (TNF- $\alpha$ )receptor-associated factor 2 (TRAF2), which couples the activation of IRE-1 $\alpha$ with different inflammatory pathways. The formation of the IRE-1 $\alpha$-TRAF2 complex mediates cross-talk between active IRE-1 $\alpha$ and the NF- $\kappa$ B and MAPK signaling pathways. TRAF2 directly interacts with IKK and indirectly with JNK by activating apoptosis signal-regulating kinase 1 (ASK1), which then coordinates the activation of JNK $[6,66]$. IRE-1 $\alpha$-mediated activation of IKK leads to the phosphorylation of $\mathrm{I} \kappa \mathrm{B}$ to promote NF- $\kappa \mathrm{B}$-dependent transcriptional regulation, while the IRE$1 \alpha$-dependent activation of JNK stimulates the bZIP transcription factor activator protein 1 (AP1). Thereafter, AP-1, a heterodimer composed of a differential combination of Fos, Jun, ATF and Maf sub-family members, binds to enhancer elements which upregulate the transcription of inflammatory genes [67].

Interestingly, the IRE-1 $\alpha$-TRAF2 axis has been shown to stimulate the nucleotide-binding oligomerization domain 1 and 2 (NOD1/2)-receptor-interacting serine/threonine-protein kinase 2 
(RIPK2) pathway, resulting in the activation of NF-kB [68]. This proposed mechanism was supported in an in vivo murine model of Brucella abortus infection. Brucella abortus induces ER stress by injecting host cells with the VceC virulence factor via its type IV secretion system. Here, Keestra-Gounder et al. demonstrated that the resulting ER stress-induced production of interleukin (IL)-6 in infected mice was dependent on TRAF2, NOD1/2 and RIPK2 interplay. These findings provided further evidence of dynamic interactions between innate immunity and UPR-induced inflammation.

In conjunction with its involvement in initiating inflammation, IRE-1 $\alpha$ can facilitate cell death through its interactions with the apoptotic proteins during ER stress [69]. IRE-1 $\alpha$-dependent activation of caspase-12 has been reported to be a dispensable contributor in the execution of ER stress-induced apoptosis in mice and rats [70-72]. Nevertheless, many human variants of caspase12 possess loss-of-function mutations that promote the synthesis of a truncated protein without functional activity, and thus may not be a significant contributor to ER stress-induced cell death in humans [72]. The IRE-1 $\alpha$-TRAF2-JNK pathway coordinates cell death by facilitating Baxdependent apoptosis and inhibiting the pro-apoptotic protein Bcl-2, while the IRE-1 $\alpha$-TRAF2-p38 branch may enhance CHOP transcriptional activity $[6,73,74]$. This understanding highlights the importance of TRAF2 in linking the UPR to a diverse range of signaling pathways to trigger the appropriate physiological response.

Recently, the interaction between PERK and Janus kinase 1 (JAK1) in the UPR was elucidated in astrocytes. It has been recognized that ER stress influences the JAK-signal transducers and activators of transcription (STAT) pathway [75, 76], however, the molecular mechanisms underlying its involvement in the context of neurodegeneration and how it alters the JAK-STAT pathway in glial cells remained to be clarified. We observed that JAK1-STAT3 
signaling in ER stressed astrocytes was dependent on PERK [77]. Transfecting astrocytes with PERK small interfering RNA, followed by treatment with thapsigargin, a noncompetitive inhibitor of the sarco/endoplasmic reticulum $\mathrm{Ca}^{2+}$ ATPase used to induce ER stress, attenuated JAK1 and STAT3 phosphorylation. Additionally, PERK knockout MEFs incubated with thapsigargin expressed significantly less phosphorylated STAT3 and STAT3-dependent inflammatory cytokines and chemokines relative to their WT counterparts. Mass spectrometry revealed that JAK1 phosphorylates PERK at tyrosine 585 and 619 in vitro. While further investigation is needed to completely unravel how STAT3 is phosphorylated by the PERK/JAK1 complex, these findings present a novel pathway implicating the UPR in driving neuroinflammation.

Each of the three ER stress sensors serves a multifunctional role in maintaining ER protein homeostasis under transient ER stress. If the cell is unable to ameliorate intrinsic protein misfolding stress, the cell will induce apoptotic pathways to avoid continuously secreting distress signals to neighboring cells. The category of stimuli or environmental conditions may be an important determinant regarding whether the cell will trigger a coordinated cell death. One must also consider that certain cell types, such as highly secretory cells, must constantly maintain an optimal ER protein folding environment, making them more susceptible to ER stress.

Chronic ER stress leads to the disproportionate activation of the ATF6, IRE-1 $\alpha$ and PERK pathways to amplify the apoptotic component of the UPR [78]. Some experimental models respond to severe ER stress by attenuating ATF6 and IRE-1 $\alpha$ signaling and augmenting PERK activation to allow apoptotic signals to dominate [78]. Because CHOP possesses a short half-life, chronic PERK activation is required to overwhelm the adaptive signals of the UPR to promote cell death $[79,80]$. Similarly, sustained IRE-1 $\alpha$ signaling has the potential to initiate apoptosis in other 
situations. While various pharmacological approaches have provided invaluable insights into the physiologic role of the UPR, more work must be done to fully appreciate how each of the branches of the UPR respond to specific stimuli and how they integrate to mediate apoptotic events.

\subsection{ER Stress in Neurodegenerative Diseases}

The activation of the UPR plays an essential role in maintaining vital biological processes within the brain during cellular stress. In fact, moderate ER stress enhances cellular protection against subsequent insult by altering the transcriptome and proteome of the cell to increase the adaptive capacity of the ER, a response called the hormetic response [81-85]. However, prolonged ER stress developed in neurodegenerative diseases is believed to disrupt the protective mechanisms of the UPR, leading to the activation of inflammatory and apoptotic programs that promote neurotoxicity. In the following sections we will briefly describe the mechanisms underlying how ER stress is generated in neurodegenerative diseases, such as Alzheimer's disease (AD), Parkinson's disease (PD), Amyotrophic Lateral Sclerosis (ALS) and Multiple Sclerosis (MS), then address its potential contribution to the development of pathological neuroinflammation. In general, ER stress is a consequence of disturbances in protein-quality control machinery, $\mathrm{ER} \mathrm{Ca}^{2+}$ dysregulation, protein-trafficking impairment or direct defects in UPR components [81].

\section{Alzheimer's Disease}

$\mathrm{AD}$ is a common age-dependent neurodegenerative disease that accounts for a significant number of reported dementia cases [86]. The pathology of $\mathrm{AD}$ is characterized by the formation of intracellular neurofibrillary tangles (NFTs) composed of hyperphosphorylated tau and the extracellular parenchymal deposition of amyloid- $\beta$ (A $\beta$ ) aggregates [87, 88]. The cytoplasmic protein tau normally serves to stabilize microtubules which form 'tracks' that facilitate 
intracellular vesicle trafficking and axonal elongation and maturation. This is highlighted by the finding that knocking down tau leads to severe neurite growth defects in primary cerebellar neurons [89]. However, certain insults cause an imbalance between the activities of tau kinases and phosphatases that lead to the abnormal phosphorylation of tau [90]. In its hyperphosphorylated state, tau becomes soluble and, in turn, polymerizes to form oligomers and/or NFTs [91]. In the case for $A \beta$ pathology, genetic studies have implicated mutations in $A \beta$ precursor protein (APP) and in the transmembrane proteins presenilin-1 (PS1) and presenilin-2 (PS2), which act as subunits for the $\gamma$-secretase complex, as the predominant genetic factors contributing to the onset of familial $\mathrm{AD}$ [92,93]. Potentially pathological A $\beta$ is liberated when APP is sequentially cleaved at the plasma membrane by $\beta$-secretase, then $\gamma$-secretase. [87]. This leads to an extracellular accumulation of either total $A \beta$ or increase relative concentrations of amyloidogenic $A \beta$, such as $A \beta 42$. Impaired clearance of $A \beta$ has also been implicated in $A D$, as it creates an imbalance of its turnover in the brain [94].

Chronic ER dysfunction is highly associated with the memory and cognitive manifestations commonly observed in different experimental models of $\mathrm{AD}[95,96]$. To this point, Ma et al. elucidated that selectively abating the expression of PERK in mice possessing AD-linked mutations in genes encoding APP and PS1 prevented the aberrant phosphorylation of eIF2 $\alpha$ [97]. This, in turn, improved synaptic plasticity and spatial memory in AD mice, consistent with the requirement for active protein translation in memory consolidation [98]. Interestingly, sXBP1 overexpression ameliorates cognitive function in the 3x Tg AD mouse model [99]. The eIF2 $\alpha$ kinases general control non-derepressible 2 (GCN2) [97] and double stranded RNA-dependent kinase (PKR) have also been implicated in memory impairment $[96,100]$. Multiple studies have demonstrated that $A \beta$ oligomers can activate PKR and induce ER stress by eliciting the TNF- $\alpha$ 
pathway $[96,101]$. Additionally, $\mathrm{A} \beta$ may stimulate $\mathrm{ER}^{\mathrm{Ca}^{2+}}$ release through ryanodine receptors and IP3 receptors, which triggers ER stress, neuronal apoptosis and mitochondrial fragmentation [102-104]. Inhibition of both GCN2 and PKR through different mechanisms significantly improves cognitive function in murine $\mathrm{AD}$ models [97, 100]. These findings suggest that pathophysiological conditions, not just ER stress, which lead to sustained eIF2 $\alpha$ phosphorylation have the potential to aggravate the cognitive abnormalities seen in $\mathrm{AD}$.

Abnormal protein aggregates interfere with the normal processes involved in protein maintenance and trafficking in models of neurodegeneration. Regarding AD, soluble tau has been shown to cause pathological ER stress by targeting and impairing components involved in ERAD [105]. Paradoxically, pre-existing ER stress also promotes NFT formation. It is well known that $A \beta$ oligomer-dependent ER stress responses can lead to the activation of different kinases, such as the serine/threonine kinase glycogen synthase kinase 3 (GSK-3) [106, 107]. This kinase (among others) is capable of subsequently phosphorylating specific epitopes on tau that contribute to the development of NFT [106, 107]. Therefore, ER stress and hyperphosphorylated tau could be induced by each other in a cycle to propagate AD pathology [108]. More recently, however, the correlation between NFT formation and AD severity had been scrutinized [109]. It seems now that soluble oligomers of tau and $\mathrm{A} \beta$ may be the primary neurotoxic agents that contribute to $\mathrm{AD}$ [109].

It has been suggested that familial AD-linked PS1 mutations suppress the activation of IRE- $1 \alpha$. This predisposes cells to become more susceptible to ER stress due, in part, to decreases in protein chaperone synthesis as a result of reduced UPR induction [110]. A study using SK-NSH cells and fibroblasts expressing a PS1 mutant associated with familial AD demonstrated that mutant PS1 also disrupts PERK activation, potentially in a similar manner as IRE-1 $\alpha$, and delays nuclear accumulation of processed ATF6 in response to ER stress [111]. The aberrantly spliced 
isoform of PS2 (PS2V) is also linked to AD. Similar to the PS1 mutations, this isoform increases the vulnerability of the cell to ER stress [112]. Alternatively, the over-expression of PS1 and PS2 mutants in cells perturbs ER calcium homeostasis, implying another mechanism by which genetic mutations in the presenilin genes contribute to $\mathrm{AD}$ [113-115]. With this in mind, there is contradictory evidence indicating that neither ablation of PS1 or expression of familial AD-linked PS1 variants impairs the expression of GRP78 mRNA and the activation of IRE1- $\alpha$ [116]. Because of limited knowledge regarding how ER stress is generated during $\mathrm{AD}$, more investigation is needed to fully appreciate how dysregulated UPR signaling contributes to the pathology of AD.

\section{Parkinson's Disease}

PD is a chronic and progressive movement disorder characterized by the selective loss of dopaminergic neurons in the substantia nigra, and the presence of intraneuronal filamentous inclusion bodies called Lewy bodies. While the development of Lewy bodies is not a definitive causative factor, they are deemed to be a pathological hallmark of PD. A post-mortem study showed that the percentage of Lewy body-containing dopaminergic neurons positive for caspase3 is significantly higher than the percentage of caspase-3-positive dopaminergic neurons without Lewy bodies, indicating that Lewy body-containing dopaminergic neurons are predisposed to undergo apoptosis [117]. A principal component of Lewy bodies in PD are the abnormal filaments of $\alpha$-synuclein, which seem to form due to different genetic factors, such as the multiplication of the SCNA locus, or non-genetic factors, such as aberrant post-translational modifications [118120].

Common mutations implicated in autosomal recessive PD reside within the Parkin gene, which encodes for an E3 ubiquitin ligase that is necessary for mitophagy [121, 122]. Studies using post-mortem brain samples and mouse models also suggest that Parkin can be inactivated by post- 
translational modifications, such as oxidation, nitrosylation and the addition of dopamine [121]. Disrupting the E3 ligase activity of Parkin or defects in PTEN-induced kinase 1, which recruits Parkin to the outer membrane of damaged mitochondria, is thought to play a critical role in the development of familial and sporadic PD, mainly through its failure to maintain mitochondrial fidelity [123]. Similarly, mutations within the gene that encodes leucine-rich repeat kinase 2 (LRRK2) have been shown to promote PD [124]. LRRK2 is a widely expressed protein important for regulating various biological processes. Mutant LRRK2 is highly associated with the onset of inherited and sporadic PD, and the resulting LRRK2-mediated toxicity may be dependent on its kinase activity [125]. Nevertheless, the mechanisms underlying its role in the pathogenesis of PD are still being unraveled.

The notion that prolonged ER stress contributes to PD pathology was first supported with the findings that neurons in toxin-induced models of PD highly expressed genes involved in the UPR [126]. It is now appreciated that $\alpha$-synuclein-induced neurotoxicity may result from nitrosative stress, accumulation of ERAD substrates and/or defective vesicular trafficking, all of which can lead to ER stress [127]. To this point, under conditions of nitrosative stress, Snitrosylation directly inactivates PDI [128]. This inactivation impairs proper protein folding and hinders PDI-mediated attenuation of neuronal cell death [128]. Moreover, the concomitant accumulation of toxic $\alpha$-synuclein oligomers in the ER further exacerbates the severity of ER stress, leading to deleterious UPR signaling [120, 129]. Some findings indicate that $\alpha$-synucleindependent ER stress is the result of blocking ER to Golgi vesicular trafficking, as preventing vesicle mobilization from the ER causes the accumulation of protein cargo within the ER lumen [130]. Targeting pathways associated with these abnormal phenotypes through pharmacological intervention in vitro has been shown to rescue neuronal loss observed in PD models [127]. 
Post-mortem analysis revealed that human PD patients exhibited greater phosphorylated PERK and eIF2 $\alpha$ in neuromelanin containing dopaminergic neurons relative to control cases [131]. In the same study, phosphorylated PERK colocalized with $\alpha$-synuclein within dopaminergic neurons derived from PD patients. PC12 cells possessing the A53T mutation in the $\alpha$-synuclein gene, a point mutation that increases the tendency of $\alpha$-synuclein to form amyloid-like fibrils, exhibit elevated levels of phosphorylated eIF2 $\alpha$, CHOP, GRP78 and active caspase-12 [132]. Treatment with the caspase inhibitor z-VAD or salubrinal, which prevents the de-phosphorylation of eIF2 $\alpha$, improved cell viability of A53T PC12 cells by attenuating apoptotic signaling [132]. Taken together, these findings suggest that pathological $\alpha$-synuclein may exacerbate disease progression by promoting excessive or unmitigated ER stress responses.

Stress-induced Parkin expression serves as a protective mechanism elicited by the UPR $[133,134]$. The use of chromatin immunoprecipitation led to the discovery that ATF4 regulates Parkin gene expression by binding to CREB/ATF sites in the Parkin promoter [134]. The resulting increase in Parkin protein protects against ER stress-induced cell death in neurons by preventing the toxic accumulation of Parkin substrates. Moreover, the protective function of Parkin could be partially explained with the discovery that Parkin promotes the production of sXBP-1, which upregulates the transcription of pro-survival genes [135]. Recent evidence indicates that Parkin controls the function of PS1 and PS2, suggesting a possible link between defective Parkin and the pathogenesis of both AD and PD [136]. LRRK2 also helps maintain neuronal integrity against induced Parkinsonism by alleviating the consequences of ER stress. Yuan et al. demonstrated that LRRK2 saves neuroblastoma cells and C. elegans dopaminergic neurons from 6-OHDA or $\alpha$ synuclein toxicity [137]. They also demonstrated that loss of function mutations in LRRK2 compromises the expression of GRP78, resulting in the hyperactivation of p38 and elevated 
neuronal death. Collectively, impairment in these protective mechanisms in neurons provides an alternative disturbance that contributes to the progression of PD.

Amyotrophic Lateral Sclerosis

ALS is a progressive neurodegenerative disease characterized by the destruction of motor neurons, which leads to paralysis and poor patient prognosis [138]. Among cases of ALS, 10\% are considered familial, while the remaining $90 \%$ of cases are sporadic [139]. A pathological hallmark of familial ALS is the formation of ubiquitinated cytoplasmic inclusions composed of misfolded superoxide dismutase-1 (SOD1) [140]. However, defects in the SOD1 gene only account for $20 \%$ of familial ALS cases, and $2 \%$ of sporadic cases $[141,142]$. An accrual of evidence now connects mutations in genes encoding chromosome 9 open reading frame 72 (C9orf72), transactive response DNA binding protein 43 (TDP43), and Fused in Sarcoma RNAbinding protein (FUS) (among others) to ALS pathology [141, 143-145]. In all, a large proportion of genetic alterations implicated in ALS promote disease onset and progression by either perturbing protein quality control mechanisms, RNA integrity or cytoskeletal dynamics [141]. As in other mutations associated with neurodegenerative diseases, ALS-associated mutations are expressed ubiquitously within the CNS (neurons and surrounding neuroglia), with strong evidence that both cell-autonomous and -nonautonomous mechanisms contribute to the progressive loss of motor neurons [141].

Mediators associated with the UPR are upregulated in the spinal cords of ALS patients and in mutant SOD1 transgenic mice [146-148]. For instance, CHOP is highly expressed in motor neurons, glial cells and spinal cords of mutant SOD1 transgenic mice [149]. A similar observation is seen in spinal cord samples of sporadic ALS patients [149]. ERAD impairment is considered a central mechanism by which mutant SOD1 induces ER stress in ALS. Here, mutant SOD1 protein 
has been shown to inhibit a specific component of the retro-translocation machinery involved in ERAD called Derlin-1 by directly interacting with its cytoplasmic C-terminus [150]. Failure to export misfolded substrates from the ER in NSC34 cells leads to their accumulation within the ER lumen, which promotes neuronal death by eliciting the IRE-1-TRAF2-ASK1 pathway [150].

Increased motor neuron loss and SOD1 aggregation is observed in SOD1 ${ }^{\mathrm{G} 85 \mathrm{R}} \mathrm{PERK}^{+/}$mice compared to SOD1 ${ }^{\mathrm{G} 85 \mathrm{R}}$ mice fully expressing PERK [151]. Interestingly, ATF4 deficiency in SOD1 ${ }^{\mathrm{G} 85 \mathrm{R}}$ mice exacerbates SOD1 aggregation, but delays disease onset and reduces the expression of pro-apoptotic genes [152]. XBP1-null NSC34 motor neurons expressing mutant SOD1 are more apt to clear mutant SOD1 aggregates [153]. Moreover, silencing XBP1 in vivo provides protection against disease progression in mutant SOD1 mice [153]. Taken together, there is contradictory evidence regarding the protective effects of the UPR in experimental models of ALS, suggesting that the extent to which the UPR contributes to ALS is context-dependent.

PDI has been shown to be upregulated in SOD1 ${ }^{\mathrm{G} 93 \mathrm{~A}}$ ALS rats and mice [154]. Furthermore, post-mortem human brain samples exhibit greater PDI expression in comparison to controls, implying that PDI is induced in response to the abnormalities associated with ALS [155]. The protective role of PDI in ALS emanates from its ability to facilitate folding of misfolded assemblies, thereby reducing SOD1 aggregate-mediated toxicity [155]. As seen in PD, PDI expressed in spinal cords of ALS patients is highly S-nitrosylated [156]. Increased RNS production has been reported in ALS, and the resulting nitrosative stress may impair the function of PDI through this post-translational modification [157].

Aggregates composed of mutant TDP-43, FUS or C9orf72 also initiate the UPR program [158-160]. To this point, overexpressing ALS-associated mutant TDP-43 in Neuro2a neuroblastoma cells results in greater induction of CHOP, XBP1 and ATF6 [159]. Moreover, 
mutations in FUS contribute to the formation of cytoplasmic protein inclusions that trigger ER stress responses in NSC34 motor neurons, and are found to co-localize with PDI in post-mortem spinal cord samples from ALS patients [161, 162]. Lastly, a study expressing poly(GA) repeats in neuronal cultures, which model ALS-associated repeat expansions in the C9orf72 gene, contribute to neuronal death by inducing ER stress [158]. When treated with salubrinal or the chemical chaperone TUDCA, these neurons are rescued from ER stress-mediated cell death, indicating that mutations in the C9orf72 gene contribute to neurotoxicity by promoting ER dysfunction [158]. Overall, these findings highlight how pathological assemblies implicated in ALS contribute to motor neuron loss. Even with the present understanding that SOD1-linked mutations only account for a relatively small proportion of ALS cases, many studies investigating the relationship between ER stress and ALS largely utilize animal models expressing mutant SOD1. Therefore, it will be of importance to further elucidate the mechanisms by which ER stress is generated in other ALS models in order to fully grasp how ER stress aggravates ALS pathology.

\section{Multiple Sclerosis}

MS is T lymphocyte-mediated autoimmune disease characterized by the spatiotemporal dissemination of white matter lesions within the CNS [163]. While the etiology of MS remains in question, it is thought to be initiated by autoreactive T lymphocytes that have breached the blood brain barrier $(\mathrm{BBB})$ or the blood-cerebral spinal fluid-barrier and have mounted an autoimmune response directed toward self-CNS antigens [164]. Autoreactive B cells and innate immune cells, such as NK cells, have also been reported to localize to the CNS from the periphery during MS pathology [165]. In the early stages of MS, peripheral humoral and innate immune cells accumulate in the perivascular and ventricular spaces that separate the blood vessels from the adjacent brain tissue, reactivated by local antigen presenting cells and subsequently move into the 
brain parenchyma to promote severe neuroinflammation [166]. These reactive immune cells release a plethora of inflammatory mediators, including nitric oxide, ROS and inflammatory cytokines, which impair neuronal function and activates CNS-resident astrocytes and microglia. Together, the continuous secretion of soluble inflammatory mediators promotes the development of a neurotoxic microenvironment that facilitates demyelination, axonal degeneration and oligodendrocyte and neuronal death.

One explanation for the development of autoreactive $\mathrm{T}$ and $\mathrm{B}$ cells is that some viral antigens presented by major histocompatibility complex II in the periphery or the CNS share homology with that of myelin components. Effector lymphocytes that enter the perivascular space are reactivated by antigen presenting cells presenting myelin peptides that share sequence and structural similarities with foreign-peptides [167]. This phenomenon, molecular mimicry, is considered a potential mechanism by which pathogens break self-immunological tolerance and induce an autoimmune reaction. Pathogens sharing high degrees of peptide similarity with myelinderived peptides include Human Herpes virus type 6 and Epstein Barr virus [168]. The inflammatory milieu brought about by infiltrating innate immune cells and reactive T lymphocytes in the initial stages of the disease promotes further $T$ cell polarization to the $T_{H} 1$ or $T_{H} 17$ subsets to amplify neuronal damage. From a genetic standpoint, single polymorphisms within specific candidate genes increase the susceptibility of individuals to developing MS. Such candidate genes may include genes located within the human leukocyte antigen (HLA) locus and immunological non-HLA genes involved in central tolerance, cytokine production and homeostatic proliferation [163].

Real time qPCR analysis of CNS tissue from MS patients has revealed that the ER stress markers ATF4, GRP78 and CHOP are significantly upregulated in the white matter of MS patients 
relative to tissue from non-MS individuals [169]. In agreement with these findings, a study performing detailed semiquantitative immunohistochemical and molecular analysis on multiple CNS cell-types in active MS lesions found that GRP78 and CHOP were highly upregulated in astrocytes, microglia and oligodendrocytes [170]. The elevated expression of UPR markers in MS lesions points toward a possible link between impaired ER proteostasis and the development of active lesions.

There are multiple potential events hypothesized to induce ER stress during MS. Glutamate excitotoxicity is an important mechanism that contributes to autoimmune demyelination and lesion formation [171]. Glutamate induces the expression of GRP78, and GRP78 knockdown leads to a significant increase in excitotoxicity-induced apoptosis [172]. This suggests that glutamate excitotoxicity promotes neuronal death through an ER stress-dependent mechanism, and the upregulation of GRP78 helps neurons cope with the excessive amounts of glutamate. In accordance, GRP78 seems to be vital for maintaining cell survival during MS. Oligodendrocyteselective heterozygous deletion of GRP78 in mice induced with experimental autoimmune encephalomyelitis (EAE), an experimental model used to mimic the symptoms of MS, aggravates disease severity and enhances oligodendrocyte death [173].

Hypoxia is another potential ER stress inducer that is characteristic in, though not restricted to, MS. Histological evidence points toward a similar hypoxic-type response in diseased tissue of MS patients, as the hypoxia-related antigen D-110 is strongly expressed in tissue also expressing high levels of CHOP [170]. Alternatively, expression of human endogenous retrovirus (HERV) envelop proteins may contribute to the pathology of MS by initiating neuroinflammatory and ER stress responses in the brain $[174,175]$. For instance, the overexpression of the HERV envelope glycoprotein Syncytin-1 causes astrocytes to upregulate ER stress responses and the production of 
proinflammatory mediators that promote oligodendrocyte toxicity [175]. Finally, the inflammatory environment in the CNS could trigger ER stress in highly myelinating cells, such as oligodendrocytes. Due to their high demand for lipid synthesis, mature oligodendrocytes are more susceptible to ER stress when exposed to high levels of proinflammatory mediators. It was previously demonstrated that interferon (IFN)- $\gamma$ drives ER stress and cell death in oligodendrocytes both in vitro and in vivo [176]. In this same study, mice that were haploinsufficient for PERK were more susceptible to forced expression of IFN- $\gamma$, leading to myelination defects and oligodendrocyte death. Therefore, excessive neuroinflammation may induce ER stress in myelinating cells which would not only disrupt their ability to myelinate neuronal axons, but can also lead to cell death.

\section{ER Stress-linked Inflammation in Neurodegenerative Diseases}

The development of ER stress is considered an underlying factor contributing to the clinical manifestations linked to many neurodegenerative disorders. In addition to the diseases previously described, pathological processes associated with other neuropathologies, such as prion diseases [177-180], human immunodeficiency virus associated-neurocognitive disorders (HAND) [180, 181] and a variety of lysosomal storage diseases [182], promote cellular and physiological challenges which perturb ER homeostasis. A unifying feature of all of these diseases is the presence of neuroinflammation [183-186]. While few studies have directly examined the interactions between ER stress and inflammation in the CNS, there is evidence that these processes are intimately linked [10, 187, 188].

In brain tissue, microglia and astrocytes collaborate to mediate inflammation by integrating environmental information and carrying out an appropriate response. Microglia are CNS-resident phagocytic cells derived from the yolk sac. These sentinels of the CNS are the principal innate 
immune cell in the brain and have a key role in orchestrating inflammatory responses [189-191]. Astrocytes are also considered important regulators of the CNS, as they assist in neuronal metabolism, synaptic transmission, lay down the barriers isolating the neural tissue of the brain and coordinate the finely-tuned events of neuroinflammation along with microglia [192]. These glial cells possess a diverse repertoire of innate receptors, such as scavenger receptors and pattern recognition receptors, which allow them to augment the expression of inflammatory cytokines and chemokines under metabolic stress or interaction with PAMPs or DAMPs [193, 194].

Extracellular protein aggregates or oligomers underlie the pathology of various neurodegenerative disorders, and act as "danger signals" released from apoptotic or necrotic neurons [183]. These pathological assemblies can be recognized by innate immune receptors residing on neighboring glial cells $[183,195]$. For example, $A \beta$ oligomers are perceived to act as ligands for both the TNF- $\alpha$ receptor and toll-like receptor 4 [196]. Transient substrate-receptor interaction promotes an inflammatory response that initiates debris clearance via phagocytosis by microglia [183]. However, chronic exposure to these DAMPs or internalization of abnormal protein aggregates alters the functional properties of immunocompetent microglia and astrocytes to promote a reactive phenotype [183, 197]. In MS, autoreactive peripheral immune cells initiate an inflammatory response against myelin-derived antigen and promote neurotoxicity not only by compromising neuronal integrity directly, but causing astrocytes and microglia to secrete cytokines and other inflammatory mediators that contribute to demyelination [183, 198].

While chronic ER stress in neurons largely triggers signals to initiate apoptosis, extensive ER stress in glial cells has the potential to promote an inflammatory microenvironment characteristic in neurodegenerative diseases. Consistent with the role of astrocytes in mediating immunological homeostasis through its interactions with other cell types, the ER stress-induced 
upregulation in astrocytic inflammatory processes can encourage an inflammatory M1-like phenotype in microglia [77]. Similarly, neuronal ER stress has been shown to be positively correlated with microglial activation in a traumatic brain injury rat model [199]. ER stress not only influences pathways that result in the production of inflammatory mediators, but it also alters the responsiveness of cells to immunogenic stimuli. To this point, it has been documented that the administration of both prostaglandin $\mathrm{E}_{2}$ and IFN- $\gamma$ synergizes with $\mathrm{ER}$ stress to increase the production of IL-6 in glial cells [200]. Likewise, TNF- $\alpha$ autocrine signaling during ER stress significantly enhances the apoptotic signals of the UPR [201].

PERK knockdown experiments suggest that the association between ER stressed astrocytes and microglia activation is initially dependent on PERK signaling in astrocytes [77]. PERK haploinsufficiency and partial PERK inhibition using the small molecule PERK inhibitor GSK2606414 selectively attenuates the production of ER stress-induced inflammatory cytokines and chemokines, including IL-6, C-C Motif Chemokine Ligand (CCL)2 and CCL20 [202]. Interestingly, treating ER stressed astrocytes with ISRIB, a compound which reverses the translational block of phosphorylated eIF2 $\alpha$, attenuates ER stress-induced inflammatory gene expression [202]. We propose that the inflammatory signals induced during ER stress in astrocytes significantly relies on PERK-dependent eIF2 $\alpha$ phosphorylation. These beneficial outcomes of PERK-eIF2 $\alpha$ modulation fall in line with previous studies demonstrating that treating priondiseased mice with GSK2606414 or ISRIB confers neuroprotection by partially recovering global translation rates $[203,204]$. Conversely, preventing eIF2 $\alpha$ de-phosphorylation in response to tramatic brain injury using salubrinal is beneficial and attenuates neuroinflammation [205]. While it is becoming clear that PERK signaling has an important role in the regulation of neuroinflammation and neurodegeneration, a more complete understanding of the PERK-eIF2 $\alpha$ 
pathway is needed to define the context and cell-specific roles. Therefore, manipulating the PERKeIF2 $\alpha$ axis without disturbing its homeostatic function could present an unappreciated way to alleviate aberrant neuroinflammation. 


\subsection{References}

1. Schechter I: Partial amino acid sequence of the precursor of immunoglobulin light chain programmed by messenger RNA in vitro. Science 1975, 188(4184):160-162.

2. Nyathi Y, Wilkinson BM, Pool MR: Co-translational targeting and translocation of proteins to the endoplasmic reticulum. Biochim Biophys Acta 2013, 1833(11):23922402.

3. Siegel V, Walter P: Each of the activities of signal recognition particle (SRP) is contained within a distinct domain: analysis of biochemical mutants of SRP. Cell 1988, 52(1):39-49.

4. Walter P, Blobel G: Translocation of proteins across the endoplasmic reticulum. II. Signal recognition protein (SRP) mediates the selective binding to microsomal membranes of in-vitro-assembled polysomes synthesizing secretory protein. $J$ Cell Biol 1981, 91(2 Pt 1):551-556.

5. Black BL, Jarett L, McDonald JM: The regulation of endoplasmic reticulum calcium uptake of adipocytes by cytoplasmic calcium. J Biol Chem 1981, 256(1):322-329.

6. Kim I, Xu W, Reed JC: Cell death and endoplasmic reticulum stress: disease relevance and therapeutic opportunities. Nat Rev Drug Discov 2008, 7(12):1013-1030.

7. Tu BP, Weissman JS: Oxidative protein folding in eukaryotes: mechanisms and consequences. J Cell Biol 2004, 164(3):341-346.

8. Gomez-Navarro N, Miller EA: COP-coated vesicles. Curr Biol 2016, 26(2):R54-57.

9. Ellgaard L, McCaul N, Chatsisvili A, Braakman I: Co- and Post-Translational Protein Folding in the ER. Traffic 2016, 17(6):615-638.

10. Zhang K, Kaufman RJ: From endoplasmic-reticulum stress to the inflammatory response. Nature 2008, 454(7203):455-462.

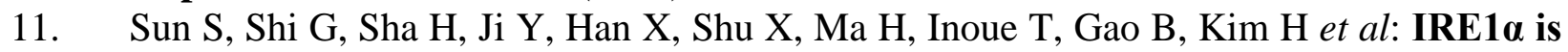
an endogenous substrate of endoplasmic-reticulum-associated degradation. Nat Cell Biol 2015, 17(12):1546-1555.

12. Harding $H$, Zhang $Y$, Ron D: Protein translation and folding are coupled by an endoplasmic-reticulum-resident kinase. Nature 1999, 397(6716):271-274.

13. Shore GC, Papa FR, Oakes SA: Signaling cell death from the endoplasmic reticulum stress response. Curr Opin Cell Biol 2011, 23(2):143-149.

14. Hitomi J, Katayama T, Eguchi Y, Kudo T, Taniguchi M, Koyama Y, Manabe T, Yamagishi $\mathrm{S}$, Bando $\mathrm{Y}$, Imaizumi $\mathrm{K}$ et al: Involvement of caspase-4 in endoplasmic reticulum stress-induced apoptosis and Abeta-induced cell death. J Cell Biol 2004, 165(3):347356.

15. Egger L, Schneider J, Rheme C, Tapernoux M, Hacki J, Borner C: Serine proteases mediate apoptosis-like cell death and phagocytosis under caspase-inhibiting conditions. Cell Death Differ 2003, 10(10):1188-1203.

16. Li J, Ni M, Lee B, Barron E, Hinton DR, Lee AS: The unfolded protein response regulator GRP78/BiP is required for endoplasmic reticulum integrity and stressinduced autophagy in mammalian cells. Cell Death Differ 2008, 15(9):1460-1471.

17. Bertolotti A, Zhang Y, Hendershot LM, Harding HP, Ron D: Dynamic interaction of BiP and ER stress transducers in the unfolded-protein response. Nat Cell Biol 2000, 2(6):326-332. 
18. Shen J, Chen X, Hendershot L, Prywes R: ER stress regulation of ATF6 localization by dissociation of BiP/GRP78 binding and unmasking of Golgi localization signals. Dev Cell 2002, 3(1):99-111.

19. Janssens S, Pulendran B, Lambrecht BN: Emerging functions of the unfolded protein response in immunity. Nat Immunol 2014, 15(10):910-919.

20. Credle JJ, Finer-Moore JS, Papa FR, Stroud RM, Walter P: On the mechanism of sensing unfolded protein in the endoplasmic reticulum. Proc Natl Acad Sci U S A 2005, 102(52):18773-18784.

21. Ron D, Walter P: Signal integration in the endoplasmic reticulum unfolded protein response. Nat Rev Mol Cell Biol 2007, 8(7):519-529.

22. Haze K, Yoshida H, Yanagi H, Yura T, Mori K: Mammalian transcription factor ATF6 is synthesized as a transmembrane protein and activated by proteolysis in response to endoplasmic reticulum stress. Mol Biol Cell 1999, 10(11):3787-3799.

23. Schröder M, Kaufman R: The mammalian unfolded protein response. Annu Rev Biochem 2005, 74:739-789.

24. Ye J, Rawson R, Komuro R, Chen X, Davé U, Prywes R, Brown M, Goldstein J: ER stress induces cleavage of membrane-bound ATF6 by the same proteases that process SREBPs. Mol Cell 2000, 6(6):1355-1364.

25. Yamamoto K, Sato T, Matsui T, Sato M, Okada T, Yoshida H, Harada A, Mori K: Transcriptional induction of mammalian ER quality control proteins is mediated by single or combined action of ATF6alpha and XBP1. Dev Cell 2007, 13(3):365-376.

26. Sidrauski C, Walter P: The transmembrane kinase Ire1p is a site-specific endonuclease that initiates mRNA splicing in the unfolded protein response. Cell 1997, 90(6):10311039.

27. Lee KP, Dey M, Neculai D, Cao C, Dever TE, Sicheri F: Structure of the dual enzyme Ire1 reveals the basis for catalysis and regulation in nonconventional RNA splicing. Cell 2008, 132(1):89-100.

28. Tirasophon W, Lee K, Callaghan B, Welihinda A, Kaufman RJ: The endoribonuclease activity of mammalian IRE1 autoregulates its mRNA and is required for the unfolded protein response. Genes \& development 2000, 14(21):2725-2736.

29. Lee K, Tirasophon W, Shen X, Michalak M, Prywes R, Okada T, Yoshida H, Mori K, Kaufman RJ: IRE1-mediated unconventional mRNA splicing and S2P-mediated ATF6 cleavage merge to regulate XBP1 in signaling the unfolded protein response. Genes \& development 2002, 16(4):452-466.

30. Yamamoto K, Yoshida H, Kokame K, Kaufman RJ, Mori K: Differential contributions of ATF6 and XBP1 to the activation of endoplasmic reticulum stress-responsive cisacting elements ERSE, UPRE and ERSE-II. J Biochem 2004, 136(3):343-350.

31. Maurel M, Chevet E, Tavernier J, Gerlo S: Getting RIDD of RNA: IRE1 in cell fate regulation. Trends Biochem Sci 2014, 39(5):245-254.

32. Hollien J, Weissman JS: Decay of endoplasmic reticulum-localized mRNAs during the unfolded protein response. Science 2006, 313(5783):104-107.

33. Han D, Lerner AG, Vande Walle L, Upton JP, Xu W, Hagen A, Backes BJ, Oakes SA, Papa FR: IRE1alpha kinase activation modes control alternate endoribonuclease outputs to determine divergent cell fates. Cell 2009, 138(3):562-575. 
34. Upton JP, Wang L, Han D, Wang ES, Huskey NE, Lim L, Truitt M, McManus MT, Ruggero D, Goga A et al: IRE1alpha cleaves select microRNAs during ER stress to derepress translation of proapoptotic Caspase-2. Science 2012, 338(6108):818-822.

35. Chen Y, Brandizzi F: IRE1: ER stress sensor and cell fate executor. Trends in cell biology 2013, 23(11):547-555.

36. Starck SR, Tsai JC, Chen K, Shodiya M, Wang L, Yahiro K, Martins-Green M, Shastri N, Walter P: Translation from the 5 ' untranslated region shapes the integrated stress response. Science 2016, 351(6272):aad3867.

37. Klann E, Dever TE: Biochemical mechanisms for translational regulation in synaptic plasticity. Nat Rev Neurosci 2004, 5(12):931-942.

38. Vattem KM, Wek RC: Reinitiation involving upstream ORFs regulates ATF4 mRNA translation in mammalian cells. Proc Natl Acad Sci U S A 2004, 101(31):11269-11274.

39. Wang M, Kaufman RJ: Protein misfolding in the endoplasmic reticulum as a conduit to human disease. Nature 2016, 529(7586):326-335.

40. Nishitoh H: CHOP is a multifunctional transcription factor in the ER stress response. J Biochem 2012, 151(3):217-219.

41. Oyadomari S, Mori M: Roles of CHOP/GADD153 in endoplasmic reticulum stress. Cell Death Differ 2004, 11(4):381-389.

42. Tabas I, Ron D: Integrating the mechanisms of apoptosis induced by endoplasmic reticulum stress. Nat Cell Biol 2011, 13(3):184-190.

43. Li G, Mongillo M, Chin K-T, Harding H, Ron D, Marks AR, Tabas I: Role of ERO1alpha-mediated stimulation of inositol 1,4,5-triphosphate receptor activity in endoplasmic reticulum stress-induced apoptosis. J Cell Biol 2009, 186(6):783-792.

44. Görlach A, Klappa P, Kietzmann T: The endoplasmic reticulum: folding, calcium homeostasis, signaling, and redox control. Antioxid Redox Signal 2006, 8(9-10):13911418.

45. Hansson MJ, Mansson R, Morota S, Uchino H, Kallur T, Sumi T, Ishii N, Shimazu M, Keep MF, Jegorov A et al: Calcium-induced generation of reactive oxygen species in brain mitochondria is mediated by permeability transition. Free Radic Biol Med 2008, 45(3):284-294.

46. Gross E, Sevier CS, Heldman N, Vitu E, Bentzur M, Kaiser CA, Thorpe C, Fass D: Generating disulfides enzymatically: reaction products and electron acceptors of the endoplasmic reticulum thiol oxidase Ero1p. Proc Natl Acad Sci U S A 2006, 103(2):299304.

47. Brush MH, Weiser DC, Shenolikar S: Growth arrest and DNA damage-inducible protein GADD34 targets protein phosphatase 1 alpha to the endoplasmic reticulum and promotes dephosphorylation of the alpha subunit of eukaryotic translation initiation factor 2. Mol Cell Biol 2003, 23(4):1292-1303.

48. Marciniak S, Yun C, Oyadomari S, Novoa I, Zhang Y, Jungreis R, Nagata K, Harding H, Ron D: CHOP induces death by promoting protein synthesis and oxidation in the stressed endoplasmic reticulum. Genes \& development 2004, 18(24):3066-3077.

49. Urra H, Dufey E, Lisbona F, Rojas-Rivera D, Hetz C: When ER stress reaches a dead end. Biochim Biophys Acta 2013, 1833(12):3507-3517.

50. Hollander MC, Zhan Q, Bae I, Fornace AJ: Mammalian GADD34, an apoptosis- and DNA damage-inducible gene. J Biol Chem 1997, 272(21):13731-13737. 
51. Cullinan SB, Diehl JA: PERK-dependent activation of Nrf2 contributes to redox homeostasis and cell survival following endoplasmic reticulum stress. $J$ Biol Chem 2004, 279(19):20108-20117.

52. Cullinan SB, Zhang D, Hannink M, Arvisais E, Kaufman RJ, Diehl JA: Nrf2 is a direct PERK substrate and effector of PERK-dependent cell survival. Mol Cell Biol 2003, 23(20):7198-7209.

53. Yoshida H, Matsui T, Yamamoto A, Okada T, Mori K: XBP1 mRNA is induced by ATF6 and spliced by IRE1 in response to ER stress to produce a highly active transcription factor. Cell 2001, 107(7):881-891.

54. Tsuru A, Imai Y, Saito M, Kohno K: Novel mechanism of enhancing IRE1alpha-XBP1 signalling via the PERK-ATF4 pathway. Sci Rep 2016, 6:24217.

55. Yoshida H, Okada T, Haze K, Yanagi H, Yura T, Negishi M, Mori K: ATF6 activated by proteolysis binds in the presence of NF-Y (CBF) directly to the cis-acting element responsible for the mammalian unfolded protein response. Mol Cell Biol 2000, 20(18):6755-6767.

56. Cnop M, Foufelle F, Velloso LA: Endoplasmic reticulum stress, obesity and diabetes. Trends in molecular medicine 2012, 18(1):59-68.

57. Bommiasamy H, Back SH, Fagone P, Lee K, Meshinchi S, Vink E, Sriburi R, Frank M, Jackowski S, Kaufman RJ et al: ATF6alpha induces XBP1-independent expansion of the endoplasmic reticulum. $J$ Cell Sci 2009, 122(Pt 10):1626-1636.

58. Trinh MA, Klann E: Translational control by eIF2 $\alpha$ kinases in long-lasting synaptic plasticity and long-term memory. Neurobiol Learn Mem 2013, 105:93-99.

59. Martínez G, Vidal RL, Mardones P, Serrano FG, Ardiles AO, Wirth C, Valdés P, Thielen P, Schneider BL, Kerr B et al: Regulation of Memory Formation by the Transcription Factor XBP1. Cell Rep 2016, 14(6):1382-1394.

60. Tang G, Minemoto Y, Dibling B, Purcell NH, Li Z, Karin M, Lin A: Inhibition of JNK activation through NF-kappaB target genes. Nature 2001, 414(6861):313-317.

61. Gilmore TD: Introduction to NF-kappaB: players, pathways, perspectives. Oncogene 2006, 25(51):6680-6684.

62. Chen Z, Hagler J, Palombella VJ, Melandri F, Scherer D, Ballard D, Maniatis T: Signalinduced site-specific phosphorylation targets I kappa B alpha to the ubiquitinproteasome pathway. Genes \& development 1995, 9(13):1586-1597.

63. Tabary O, Boncoeur E, de Martin R, Pepperkok R, Clement A, Schultz C, Jacquot J: Calcium-dependent regulation of NF-(kappa)B activation in cystic fibrosis airway epithelial cells. Cell Signal 2006, 18(5):652-660.

64. van den Berg R, Haenen GR, van den Berg H, Bast A: Transcription factor NF-kappaB as a potential biomarker for oxidative stress. Br J Nutr 2001, 86 Suppl 1:S121-127.

65. Deng J, Lu PD, Zhang Y, Scheuner D, Kaufman RJ, Sonenberg N, Harding HP, Ron D: Translational repression mediates activation of nuclear factor kappa B by phosphorylated translation initiation factor 2. Mol Cell Biol 2004, 24(23):10161-10168.

66. Urano F, Wang X, Bertolotti A, Zhang Y, Chung P, Harding H, Ron D: Coupling of stress in the ER to activation of JNK protein kinases by transmembrane protein kinase IRE1. Science 2000, 287(5453):664-666.

67. Shaulian E, Karin M: AP-1 as a regulator of cell life and death. Nat Cell Biol 2002, 4(5):E131-136. 
68. Keestra-Gounder AM, Byndloss MX, Seyffert N, Young BM, Chávez-Arroyo A, Tsai AY, Cevallos SA, Winter MG, Pham OH, Tiffany CR et al: NOD1 and NOD2 signalling links ER stress with inflammation. Nature 2016, 532(7599):394-397.

69. Hetz C, Bernasconi P, Fisher J, Lee A-H, Bassik MC, Antonsson B, Brandt GS, Iwakoshi NN, Schinzel A, Glimcher LH et al: Proapoptotic BAX and BAK modulate the unfolded protein response by a direct interaction with IRE1alpha. Science 2006, 312(5773):572576.

70. Lamkanfi M, Kalai M, Vandenabeele P: Caspase-12: an overview. Cell Death Differ 2004, 11(4):365-368.

71. Yang C, Diiorio P, Jurczyk A, O'Sullivan-Murphy B, Urano F, Bortell R: Pathological endoplasmic reticulum stress mediated by the IRE1 pathway contributes to preinsulitic beta cell apoptosis in a virus-induced rat model of type 1 diabetes. Diabetologia 2013, 56(12):2638-2646.

72. Fischer H, Koenig U, Eckhart L, Tschachler E: Human caspase 12 has acquired deleterious mutations. Biochem Biophys Res Commun 2002, 293(2):722-726.

73. Wang XZ, Ron D: Stress-induced phosphorylation and activation of the transcription factor CHOP (GADD153) by p38 MAP Kinase. Science 1996, 272(5266):1347-1349.

74. Lei K, Davis RJ: JNK phosphorylation of Bim-related members of the Bcl2 family induces Bax-dependent apoptosis. Proc Natl Acad Sci U S A 2003, 100(5):2432-2437.

75. Hosoi T, Sasaki M, Miyahara T, Hashimoto C, Matsuo S, Yoshii M, Ozawa K: Endoplasmic reticulum stress induces leptin resistance. Mol Pharmacol 2008, 74(6):1610-1619.

76. Flores-Morales A, Fernandez L, Rico-Bautista E, Umana A, Negrin C, Zhang JG, Norstedt G: Endoplasmic reticulum stress prolongs GH-induced Janus kinase (JAK2)/signal transducer and activator of transcription (STAT5) signaling pathway. Mol Endocrinol 2001, 15(9):1471-1483.

77. Meares GP, Liu Y, Rajbhandari R, Qin H, Nozell SE, Mobley JA, Corbett JA, Benveniste EN: PERK-Dependent Activation of JAK1 and STAT3 Contributes to Endoplasmic Reticulum Stress-Induced Inflammation. Mol Cell Biol 2014, 34(20):3911-3925.

78. Lin JH, Li H, Yasumura D, Cohen HR, Zhang C, Panning B, Shokat KM, Lavail MM, Walter P: IRE1 signaling affects cell fate during the unfolded protein response. Science 2007, 318(5852):944-949.

79. Wang $M$, Kaufman RJ: The impact of the endoplasmic reticulum protein-folding environment on cancer development. Nat Rev Cancer 2014, 14(9):581-597.

80. Rutkowski DT, Arnold SM, Miller CN, Wu J, Li J, Gunnison KM, Mori K, Sadighi Akha AA, Raden D, Kaufman RJ: Adaptation to ER stress is mediated by differential stabilities of pro-survival and pro-apoptotic mRNAs and proteins. PLoS Biol 2006, 4(11):e374.

81. Hetz C, Mollereau B: Disturbance of endoplasmic reticulum proteostasis in neurodegenerative diseases. Nat Rev Neurosci 2014, 15(4):233-249.

82. Inagi R, Kumagai $T$, Nishi H, Kawakami T, Miyata T, Fujita T, Nangaku M: Preconditioning with endoplasmic reticulum stress ameliorates mesangioproliferative glomerulonephritis. J Am Soc Nephrol 2008, 19(5):915-922.

83. Mercado G, Valdes P, Hetz C: An ERcentric view of Parkinson's disease. Trends in molecular medicine 2013, 19(3):165-175. 
84. Fouillet A, Levet C, Virgone A, Robin M, Dourlen P, Rieusset J, Belaidi E, Ovize M, Touret M, Nataf $S$ et al: ER stress inhibits neuronal death by promoting autophagy. Autophagy 2012, 8(6):915-926.

85. Calabrese V, Cornelius C, Dinkova-Kostova AT, Calabrese EJ, Mattson MP: Cellular stress responses, the hormesis paradigm, and vitagenes: novel targets for therapeutic intervention in neurodegenerative disorders. Antioxid Redox Signal 2010, 13(11):17631811.

86. $\quad$ Reitz C, Brayne C, Mayeux R: Epidemiology of Alzheimer disease. Nat Rev Neurol 2011, 7(3):137-152.

87. De Strooper B: Proteases and proteolysis in Alzheimer disease: a multifactorial view on the disease process. Physiol Rev 2010, 90(2):465-494.

88. Jucker M, Walker LC: Self-propagation of pathogenic protein aggregates in neurodegenerative diseases. Nature 2013, 501(7465):45-51.

89. Caceres A, Kosik KS: Inhibition of neurite polarity by tau antisense oligonucleotides in primary cerebellar neurons. Nature 1990, 343(6257):461-463.

90. Stoothoff WH, Johnson GV: Tau phosphorylation: physiological and pathological consequences. Biochim Biophys Acta 2005, 1739(2-3):280-297.

91. Gong CX, Iqbal K: Hyperphosphorylation of microtubule-associated protein tau: a promising therapeutic target for Alzheimer disease. Curr Med Chem 2008, 15(23):2321-2328.

92. Veugelen S, Saito T, Saido TC, Chávez-Gutiérrez L, De Strooper B: Familial Alzheimer's Disease Mutations in Presenilin Generate Amyloidogenic A $\beta$ Peptide Seeds. Neuron 2016, 90(2):410-416.

93. Weggen S, Beher D: Molecular consequences of amyloid precursor protein and presenilin mutations causing autosomal-dominant Alzheimer's disease. Alzheimers Res Ther 2012, 4(2):9.

94. Mawuenyega KG, Sigurdson W, Ovod V, Munsell L, Kasten T, Morris JC, Yarasheski KE, Bateman RJ: Decreased clearance of CNS beta-amyloid in Alzheimer's disease. Science 2010, 330(6012):1774.

95. Duran-Aniotz C, Martinez G, Hetz C: Memory loss in Alzheimer's disease: are the alterations in the UPR network involved in the cognitive impairment? Front Aging Neurosci 2014, 6:8.

96. Lourenco MV, Clarke JR, Frozza RL, Bomfim TR, Forny-Germano L, Batista AF, Sathler LB, Brito-Moreira J, Amaral OB, Silva CA et al: TNF-alpha mediates PKR-dependent memory impairment and brain IRS-1 inhibition induced by Alzheimer's betaamyloid oligomers in mice and monkeys. Cell Metab 2013, 18(6):831-843.

97. Ma T, Trinh MA, Wexler AJ, Bourbon C, Gatti E, Pierre P, Cavener DR, Klann E: Suppression of eIF2 $\alpha$ kinases alleviates Alzheimer's disease-related plasticity and memory deficits. Nat Neurosci 2013, 16(9):1299-1305.

98. Costa-Mattioli M, Sossin WS, Klann E, Sonenberg N: Translational control of longlasting synaptic plasticity and memory. Neuron 2009, 61(1):10-26.

99. Cissé M, Duplan E, Lorivel T, Dunys J, Bauer C, Meckler X, Gerakis Y, Lauritzen I, Checler F: The transcription factor XBP1s restores hippocampal synaptic plasticity and memory by control of the Kalirin-7 pathway in Alzheimer model. Mol Psychiatry 2016. 
100. Segev Y, Barrera I, Ounallah-Saad H, Wibrand K, Sporild I, Livne A, Rosenberg T, David O, Mints M, Bramham CR et al: PKR Inhibition Rescues Memory Deficit and ATF4 Overexpression in ApoE epsilon4 Human Replacement Mice. J Neurosci 2015, 35(38):12986-12993.

101. Bomfim TR, Forny-Germano L, Sathler LB, Brito-Moreira J, Houzel JC, Decker H, Silverman MA, Kazi H, Melo HM, McClean PL et al: An anti-diabetes agent protects the mouse brain from defective insulin signaling caused by Alzheimer's diseaseassociated Abeta oligomers. The Journal of clinical investigation 2012, 122(4):13391353.

102. Ferreiro E, Oliveira CR, Pereira C: Involvement of endoplasmic reticulum Ca2+ release through ryanodine and inositol 1,4,5-triphosphate receptors in the neurotoxic effects induced by the amyloid-beta peptide. J Neurosci Res 2004, 76(6):872-880.

103. Paula-Lima AC, Adasme T, SanMartín C, Sebollela A, Hetz C, Carrasco MA, Ferreira ST, Hidalgo C: Amyloid $\beta$-peptide oligomers stimulate RyR-mediated Ca2+ release inducing mitochondrial fragmentation in hippocampal neurons and prevent RyRmediated dendritic spine remodeling produced by BDNF. Antioxid Redox Signal 2011, 14(7):1209-1223.

104. Demuro A, Parker I: Cytotoxicity of intracellular aß42 amyloid oligomers involves $\mathrm{Ca} 2+$ release from the endoplasmic reticulum by stimulated production of inositol trisphosphate. J Neurosci 2013, 33(9):3824-3833.

105. Abisambra JF, Jinwal UK, Blair LJ, O'Leary JC, Li Q, Brady S, Wang L, Guidi CE, Zhang $\mathrm{B}$, Nordhues BA et al: Tau accumulation activates the unfolded protein response by impairing endoplasmic reticulum-associated degradation. $J$ Neurosci 2013, 33(22):9498-9507.

106. Nijholt DAT, Nölle A, van Haastert ES, Edelijn H, Toonen RF, Hoozemans JJM, Scheper W: Unfolded protein response activates glycogen synthase kinase-3 via selective lysosomal degradation. Neurobiol Aging 2013, 34(7):1759-1771.

107. Resende R, Ferreiro E, Pereira C, Oliveira C: ER stress is involved in Abeta-induced GSK-3beta activation and tau phosphorylation. J Neurosci Res 2008, 86(9):2091-2099.

108. Ho Y-S, Yang X, Lau JC-F, Hung CH-L, Wuwongse S, Zhang Q, Wang J, Baum L, So KF, Chang RC-C: Endoplasmic reticulum stress induces tau pathology and forms a vicious cycle: implication in Alzheimer's disease pathogenesis. J Alzheimers Dis 2012, 28(4):839-854.

109. Lasagna-Reeves CA, Castillo-Carranza DL, Guerrero-Muoz MJ, Jackson GR, Kayed R: Preparation and characterization of neurotoxic tau oligomers. Biochemistry 2010, 49(47):10039-10041.

110. Katayama T, Imaizumi K, Sato N, Miyoshi K, Kudo T, Hitomi J, Morihara T, Yoneda T, Gomi F, Mori Y et al: Presenilin-1 mutations downregulate the signalling pathway of the unfolded-protein response. Nat Cell Biol 1999, 1(8):479-485.

111. Katayama T, Imaizumi K, Honda A, Yoneda T, Kudo T, Takeda M, Mori K, Rozmahel R, Fraser P, George-Hyslop PS et al: Disturbed activation of endoplasmic reticulum stress transducers by familial Alzheimer's disease-linked presenilin-1 mutations. $J$ Biol Chem 2001, 276(46):43446-43454.

112. Sato N, Imaizumi K, Manabe T, Taniguchi M, Hitomi J, Katayama T, Yoneda T, Morihara $\mathrm{T}$, Yasuda $\mathrm{Y}$, Takagi $\mathrm{T}$ et al: Increased production of beta-amyloid and vulnerability 
to endoplasmic reticulum stress by an aberrant spliced form of presenilin 2. $\mathrm{J}$ Biol Chem 2001, 276(3):2108-2114.

113. Paschen W, Mengesdorf $\mathrm{T}$ : Endoplasmic reticulum stress response and neurodegeneration. Cell Calcium 2005, 38(3-4):409-415.

114. Mattson MP, Zhu H, Yu J, Kindy MS: Presenilin-1 mutation increases neuronal vulnerability to focal ischemia in vivo and to hypoxia and glucose deprivation in cell culture: involvement of perturbed calcium homeostasis. J Neurosci 2000, 20(4):13581364.

115. Zatti G, Ghidoni R, Barbiero L, Binetti G, Pozzan T, Fasolato C, Pizzo P: The presenilin 2 M239I mutation associated with familial Alzheimer's disease reduces Ca2+ release from intracellular stores. Neurobiol Dis 2004, 15(2):269-278.

116. Sato N, Urano F, Yoon Leem J, Kim SH, Li M, Donoviel D, Bernstein A, Lee AS, Ron D, Veselits ML et al: Upregulation of BiP and CHOP by the unfolded-protein response is independent of presenilin expression. Nat Cell Biol 2000, 2(12):863-870.

117. Hartmann A, Hunot S, Michel PP, Muriel MP, Vyas S, Faucheux BA, Mouatt-Prigent A, Turmel H, Srinivasan A, Ruberg $\mathrm{M}$ et al: Caspase-3: A vulnerability factor and final effector in apoptotic death of dopaminergic neurons in Parkinson's disease. Proc Natl Acad Sci U S A 2000, 97(6):2875-2880.

118. Schildknecht S, Gerding HR, Karreman C, Drescher M, Lashuel HA, Outeiro TF, Di Monte DA, Leist M: Oxidative and nitrative alpha-synuclein modifications and proteostatic stress: implications for disease mechanisms and interventions in synucleinopathies. $J$ Neurochem 2013, 125(4):491-511.

119. Chartier-Harlin MC, Kachergus J, Roumier C, Mouroux V, Douay X, Lincoln S, Levecque $\mathrm{C}$, Larvor L, Andrieux J, Hulihan $\mathrm{M}$ et al: Alpha-synuclein locus duplication as a cause of familial Parkinson's disease. Lancet 2004, 364(9440):1167-1169.

120. Michel PP, Hirsch EC, Hunot S: Understanding Dopaminergic Cell Death Pathways in Parkinson Disease. Neuron 2016, 90(4):675-691.

121. Scarffe LA, Stevens DA, Dawson VL, Dawson TM: Parkin and PINK1: much more than mitophagy. Trends Neurosci 2014, 37(6):315-324.

122. Corti O, Brice A: Mitochondrial quality control turns out to be the principal suspect in parkin and PINK1-related autosomal recessive Parkinson's disease. Curr Opin Neurobiol 2013, 23(1):100-108.

123. Pickrell AM, Youle RJ: The roles of PINK1, parkin, and mitochondrial fidelity in Parkinson's disease. Neuron 2015, 85(2):257-273.

124. Zimprich A, Biskup S, Leitner P, Lichtner P, Farrer M, Lincoln S, Kachergus J, Hulihan M, Uitti RJ, Calne DB et al: Mutations in LRRK2 cause autosomal-dominant parkinsonism with pleomorphic pathology. Neuron 2004, 44(4):601-607.

125. Lee BD, Shin J-H, VanKampen J, Petrucelli L, West AB, Ko HS, Lee Y-I, Maguire-Zeiss KA, Bowers WJ, Federoff HJ et al: Inhibitors of leucine-rich repeat kinase-2 protect against models of Parkinson's disease. Nat Med 2010, 16(9):998-1000.

126. Ryu EJ, Harding HP, Angelastro JM, Vitolo OV, Ron D, Greene LA: Endoplasmic reticulum stress and the unfolded protein response in cellular models of Parkinson's disease. J Neurosci 2002, 22(24):10690-10698.

127. Chung CY, Khurana V, Auluck PK, Tardiff DF, Mazzulli JR, Soldner F, Baru V, Lou Y, Freyzon $\mathrm{Y}$, Cho $\mathrm{S}$ et al: Identification and rescue of $\alpha$-synuclein toxicity in Parkinson patient-derived neurons. Science 2013, 342(6161):983-987. 
128. Uehara T, Nakamura T, Yao D, Shi Z-Q, Gu Z, Ma Y, Masliah E, Nomura Y, Lipton SA: S-nitrosylated protein-disulphide isomerase links protein misfolding to neurodegeneration. Nature 2006, 441(7092):513-517.

129. Colla E, Jensen PH, Pletnikova O, Troncoso JC, Glabe C, Lee MK: Accumulation of toxic alpha-synuclein oligomer within endoplasmic reticulum occurs in alphasynucleinopathy in vivo. $J$ Neurosci 2012, 32(10):3301-3305.

130. Cooper AA, Gitler AD, Cashikar A, Haynes CM, Hill KJ, Bhullar B, Liu K, Xu K, Strathearn KE, Liu F et al: Alpha-synuclein blocks ER-Golgi traffic and Rab1 rescues neuron loss in Parkinson's models. Science 2006, 313(5785):324-328.

131. Hoozemans JJM, van Haastert ES, Eikelenboom P, de Vos RAI, Rozemuller JM, Scheper $\mathrm{W}$ : Activation of the unfolded protein response in Parkinson's disease. Biochem Biophys Res Commun 2007, 354(3):707-711.

132. Smith WW, Jiang H, Pei Z, Tanaka Y, Morita H, Sawa A, Dawson VL, Dawson TM, Ross CA: Endoplasmic reticulum stress and mitochondrial cell death pathways mediate A53T mutant alpha-synuclein-induced toxicity. Human molecular genetics 2005, 14(24):3801-3811.

133. Imai Y, Soda M, Takahashi R: Parkin suppresses unfolded protein stress-induced cell death through its E3 ubiquitin-protein ligase activity. J Biol Chem 2000, 275(46):35661-35664.

134. Bouman L, Schlierf A, Lutz AK, Shan J, Deinlein A, Kast J, Galehdar Z, Palmisano V, Patenge N, Berg D et al: Parkin is transcriptionally regulated by ATF4: evidence for an interconnection between mitochondrial stress and ER stress. Cell Death Differ 2011, 18(5):769-782.

135. Duplan E, Giaime E, Viotti J, Sevalle J, Corti O, Brice A, Ariga H, Qi L, Checler F, Alves da Costa C: ER-stress-associated functional link between Parkin and DJ-1 via a transcriptional cascade involving the tumor suppressor p53 and the spliced X-box binding protein XBP-1. $J$ Cell Sci 2013, 126(Pt 9):2124-2133.

136. Duplan E, Sevalle J, Viotti J, Goiran T, Bauer C, Renbaum P, Levy-Lahad E, Gautier CA, Corti $\mathrm{O}$, Leroudier $\mathrm{N}$ et al: Parkin differently regulates presenilin-1 and presenilin-2 functions by direct control of their promoter transcription. J Mol Cell Biol 2013, 5(2):132-142.

137. Yuan Y, Cao P, Smith MA, Kramp K, Huang Y, Hisamoto N, Matsumoto K, Hatzoglou $M$, Jin $H$, Feng Z: Dysregulated LRRK2 signaling in response to endoplasmic reticulum stress leads to dopaminergic neuron degeneration in C. elegans. PLoS One 2011, 6(8):e22354.

138. Matus S, Valenzuela V, Medinas DB, Hetz C: ER Dysfunction and Protein Folding Stress in ALS. Int J Cell Biol 2013, 2013:674751.

139. Zarei S, Carr K, Reiley L, Diaz K, Guerra O, Altamirano PF, Pagani W, Lodin D, Orozco G, Chinea A: A comprehensive review of amyotrophic lateral sclerosis. Surg Neurol Int 2015, 6:171.

140. Deng HX, Hentati A, Tainer JA, Iqbal Z, Cayabyab A, Hung WY, Getzoff ED, Hu P, Herzfeldt B, Roos RP: Amyotrophic lateral sclerosis and structural defects in Cu,Zn superoxide dismutase. Science 1993, 261(5124):1047-1051.

141. Taylor JP, Brown RH, Jr., Cleveland DW: Decoding ALS: from genes to mechanism. Nature 2016, 539(7628):197-206. 
142. Rosen DR, Siddique T, Patterson D, Figlewicz DA, Sapp P, Hentati A, Donaldson D, Goto J, O'Regan JP, Deng HX et al: Mutations in $\mathrm{Cu} / \mathrm{Zn}$ superoxide dismutase gene are associated with familial amyotrophic lateral sclerosis. Nature 1993, 362(6415):59-62.

143. Rosen DR: Mutations in $\mathrm{Cu} / \mathrm{Zn}$ superoxide dismutase gene are associated with familial amyotrophic lateral sclerosis. Nature 1993, 364(6435):362.

144. Renton AE, Majounie E, Waite A, Simón-Sánchez J, Rollinson S, Gibbs JR, Schymick JC, Laaksovirta H, van Swieten JC, Myllykangas L et al: A hexanucleotide repeat expansion in C9ORF72 is the cause of chromosome 9p21-linked ALS-FTD. Neuron 2011, 72(2):257-268.

145. Kwiatkowski TJ, Bosco DA, Leclerc AL, Tamrazian E, Vanderburg CR, Russ C, Davis A, Gilchrist J, Kasarskis EJ, Munsat $\mathrm{T}$ et al: Mutations in the FUS/TLS gene on chromosome 16 cause familial amyotrophic lateral sclerosis. Science 2009, 323(5918):1205-1208.

146. Matus S, Glimcher LH, Hetz C: Protein folding stress in neurodegenerative diseases: a glimpse into the ER. Curr Opin Cell Biol 2011, 23(2):239-252.

147. Ilieva EV, Ayala V, Jové M, Dalfó E, Cacabelos D, Povedano M, Bellmunt MJ, Ferrer I, Pamplona R, Portero-Otín M: Oxidative and endoplasmic reticulum stress interplay in sporadic amyotrophic lateral sclerosis. Brain 2007, 130(Pt 12):3111-3123.

148. Atkin JD, Farg MA, Walker AK, McLean C, Tomas D, Horne MK: Endoplasmic reticulum stress and induction of the unfolded protein response in human sporadic amyotrophic lateral sclerosis. Neurobiol Dis 2008, 30(3):400-407.

149. Ito Y, Yamada M, Tanaka H, Aida K, Tsuruma K, Shimazawa M, Hozumi I, Inuzuka T, Takahashi H, Hara H: Involvement of CHOP, an ER-stress apoptotic mediator, in both human sporadic ALS and ALS model mice. Neurobiol Dis 2009, 36(3):470-476.

150. Nishitoh H, Kadowaki H, Nagai A, Maruyama T, Yokota T, Fukutomi H, Noguchi T, Matsuzawa A, Takeda K, Ichijo H: ALS-linked mutant SOD1 induces ER stress- and ASK1-dependent motor neuron death by targeting Derlin-1. Genes \& development 2008, 22(11):1451-1464.

151. Wang L, Popko B, Roos RP: The unfolded protein response in familial amyotrophic lateral sclerosis. Hum Mol Genet 2011, 20(5):1008-1015.

152. Matus S, Lopez E, Valenzuela V, Nassif M, Hetz C: Functional contribution of the transcription factor ATF4 to the pathogenesis of amyotrophic lateral sclerosis. PLoS One 2013, 8(7):e66672.

153. Hetz C, Thielen P, Matus S, Nassif M, Court F, Kiffin R, Martinez G, Cuervo AM, Brown $\mathrm{RH}$, Glimcher LH: XBP-1 deficiency in the nervous system protects against amyotrophic lateral sclerosis by increasing autophagy. Genes Dev 2009, 23(19):22942306.

154. Atkin JD, Farg MA, Turner BJ, Tomas D, Lysaght JA, Nunan J, Rembach A, Nagley P, Beart PM, Cheema SS et al: Induction of the unfolded protein response in familial amyotrophic lateral sclerosis and association of protein-disulfide isomerase with superoxide dismutase 1. J Biol Chem 2006, 281(40):30152-30165.

155. Walker AK, Farg MA, Bye CR, McLean CA, Horne MK, Atkin JD: Protein disulphide isomerase protects against protein aggregation and is S-nitrosylated in amyotrophic lateral sclerosis. Brain 2010, 133(Pt 1):105-116. 
156. Halloran M, Parakh S, Atkin JD: The role of s-nitrosylation and s-glutathionylation of protein disulphide isomerase in protein misfolding and neurodegeneration. Int J Cell Biol 2013, 2013:797914.

157. Parakh S, Atkin JD: Protein folding alterations in amyotrophic lateral sclerosis. Brain Res 2016, 1648(Pt B):633-649.

158. Zhang YJ, Jansen-West K, Xu YF, Gendron TF, Bieniek KF, Lin WL, Sasaguri H, Caulfield T, Hubbard J, Daughrity L et al: Aggregation-prone c9FTD/ALS poly(GA) RAN-translated proteins cause neurotoxicity by inducing ER stress. Acta Neuropathol 2014, 128(4):505-524.

159. Walker AK, Soo KY, Sundaramoorthy V, Parakh S, Ma Y, Farg MA, Wallace RH, Crouch PJ, Turner BJ, Horne MK et al: ALS-associated TDP-43 induces endoplasmic reticulum stress, which drives cytoplasmic TDP-43 accumulation and stress granule formation. PLoS One 2013, 8(11):e81170.

160. Farg MA, Sundaramoorthy V, Sultana JM, Yang S, Atkinson RA, Levina V, Halloran MA, Gleeson PA, Blair IP, Soo KY et al: C9ORF72, implicated in amytrophic lateral sclerosis and frontotemporal dementia, regulates endosomal trafficking. Hum $\mathrm{Mol}$ Genet 2014, 23(13):3579-3595.

161. Dormann D, Rodde R, Edbauer D, Bentmann E, Fischer I, Hruscha A, Than ME, Mackenzie IR, Capell A, Schmid B et al: ALS-associated fused in sarcoma (FUS) mutations disrupt Transportin-mediated nuclear import. EMBO J 2010, 29(16):28412857.

162. Farg MA, Soo KY, Walker AK, Pham H, Orian J, Horne MK, Warraich ST, Williams KL, Blair IP, Atkin JD: Mutant FUS induces endoplasmic reticulum stress in amyotrophic lateral sclerosis and interacts with protein disulfide-isomerase. Neurobiol Aging 2012, 33(12):2855-2868.

163. Dendrou CA, Fugger L, Friese MA: Immunopathology of multiple sclerosis. Nat Rev Immunol 2015, 15(9):545-558.

164. Ransohoff RM, Kivisakk P, Kidd G: Three or more routes for leukocyte migration into the central nervous system. Nat Rev Immunol 2003, 3(7):569-581.

165. Hoglund RA, Maghazachi AA: Multiple sclerosis and the role of immune cells. World $J$ Exp Med 2014, 4(3):27-37.

166. Goverman J: Autoimmune $\mathbf{T}$ cell responses in the central nervous system. Nat Rev Immunol 2009, 9(6):393-407.

167. Libbey JE, McCoy LL, Fujinami RS: Molecular mimicry in multiple sclerosis. Int Rev Neurobiol 2007, 79:127-147.

168. Virtanen JO, Jacobson S: Viruses and multiple sclerosis. CNS Neurol Disord Drug Targets 2012, 11(5):528-544.

169. Cunnea P, Mháille AN, McQuaid S, Farrell M, McMahon J, FitzGerald U: Expression profiles of endoplasmic reticulum stress-related molecules in demyelinating lesions and multiple sclerosis. Mult Scler 2011, 17(7):808-818.

170. Mháille AN, McQuaid S, Windebank A, Cunnea P, McMahon J, Samali A, FitzGerald U: Increased expression of endoplasmic reticulum stress-related signaling pathway molecules in multiple sclerosis lesions. $J$ Neuropathol Exp Neurol 2008, 67(3):200-211.

171. Werner P, Pitt D, Raine CS: Glutamate excitotoxicity--a mechanism for axonal damage and oligodendrocyte death in Multiple Sclerosis? J Neural Transm Suppl 2000(60):375385. 
172. Yu Z, Luo H, Fu W, Mattson MP: The endoplasmic reticulum stress-responsive protein GRP78 protects neurons against excitotoxicity and apoptosis: suppression of oxidative stress and stabilization of calcium homeostasis. Experimental neurology 1999, 155(2):302-314.

173. Hussien Y, Podojil JR, Robinson AP, Lee AS, Miller SD, Popko B: ER Chaperone BiP/GRP78 Is Required for Myelinating Cell Survival and Provides Protection during Experimental Autoimmune Encephalomyelitis. J Neurosci 2015, 35(48):1592115933.

174. Dimcheff DE, Faasse MA, McAtee FJ, Portis JL: Endoplasmic reticulum (ER) stress induced by a neurovirulent mouse retrovirus is associated with prolonged $\mathrm{BiP}$ binding and retention of a viral protein in the ER. $J$ Biol Chem 2004, 279(32):3378233790.

175. Deslauriers AM, Afkhami-Goli A, Paul AM, Bhat RK, Acharjee S, Ellestad KK, Noorbakhsh F, Michalak M, Power C: Neuroinflammation and endoplasmic reticulum stress are coregulated by crocin to prevent demyelination and neurodegeneration. $J$ Immunol 2011, 187(9):4788-4799.

176. Lin W, Harding HP, Ron D, Popko B: Endoplasmic reticulum stress modulates the response of myelinating oligodendrocytes to the immune cytokine interferon-gamma. J Cell Biol 2005, 169(4):603-612.

177. Xu K, Zhu XP: Endoplasmic reticulum stress and prion diseases. Rev Neurosci 2012, 23(1):79-84.

178. Torres M, Castillo K, Armisen R, Stutzin A, Soto C, Hetz C: Prion protein misfolding affects calcium homeostasis and sensitizes cells to endoplasmic reticulum stress. PLOS One 2010, 5(12): 15658.

179. Torres M, Encina G, Soto C, Hetz C: Abnormal calcium homeostasis and protein folding stress at the ER: A common factor in familial and infectious prion disorders. Commun Integr Biol 2011, 4(3):258-261.

180. Cai Y, Arikkath J, Yang L, Guo ML, Periyasamy P, Buch S: Interplay of endoplasmic reticulum stress and autophagy in neurodegenerative disorders. Autophagy 2016, 12(2):225-244.

181. Akay C, Lindl KA, Shyam N, Nabet B, Goenaga-Vazquez Y, Ruzbarsky J, Wang Y, Kolson DL, Jordan-Sciutto KL: Activation status of integrated stress response pathways in neurones and astrocytes of HIV-associated neurocognitive disorders (HAND) cortex. Neuropathology and applied neurobiology 2012, 38(2):175-200.

182. Wei H, Kim S-J, Zhang Z, Tsai P-C, Wisniewski KE, Mukherjee AB: ER and oxidative stresses are common mediators of apoptosis in both neurodegenerative and nonneurodegenerative lysosomal storage disorders and are alleviated by chemical chaperones. Human molecular genetics 2008, 17(4):469-477.

183. Glass CK, Saijo K, Winner B, Marchetto MC, Gage FH: Mechanisms underlying inflammation in neurodegeneration. Cell 2010, 140(6):918-934.

184. Bosch ME, Kielian T: Neuroinflammatory paradigms in lysosomal storage diseases. Front Neurosci 2015, 9:417.

185. Riemer C, Gültner S, Heise I, Holtkamp N, Baier M: Neuroinflammation in prion diseases: concepts and targets for therapeutic intervention. CNS Neurol Disord Drug Targets 2009, 8(5):329-341. 
186. Gannon P, Khan MZ, Kolson DL: Current understanding of HIV-associated neurocognitive disorders pathogenesis. Curr Opin Neurol 2011, 24(3):275-283.

187. Martinon F, Glimcher LH: Regulation of innate immunity by signaling pathways emerging from the endoplasmic reticulum. Curr Opin Immunol 2011, 23(1):35-40.

188. Zanetti M, Rodvold JJ, Mahadevan NR: The evolving paradigm of cell-nonautonomous UPR-based regulation of immunity by cancer cells. Oncogene 2016, 35(3):269-278.

189. Alliot F, Godin I, Pessac B: Microglia derive from progenitors, originating from the yolk sac, and which proliferate in the brain. Brain Res Dev Brain Res 1999, 117(2):145152.

190. Kawabori M, Yenari MA: The role of the microglia in acute CNS injury. Metab Brain Dis 2015, 30(2):381-392.

191. Katsumoto A, Lu H, Miranda AS, Ransohoff RM: Ontogeny and functions of central nervous system macrophages. J Immunol 2014, 193(6):2615-2621.

192. Sofroniew MV: Astrocyte barriers to neurotoxic inflammation. Nat Rev Neurosci 2015, 16(5):249-263.

193. Miranda-Hernandez S, Baxter AG: Role of toll-like receptors in multiple sclerosis. Am J Clin Exp Immunol 2013, 2(1):75-93.

194. Farina C, Aloisi F, Meinl E: Astrocytes are active players in cerebral innate immunity. Trends Immunol 2007, 28(3):138-145.

195. Bjorkqvist M, Wild EJ, Thiele J, Silvestroni A, Andre R, Lahiri N, Raibon E, Lee RV, Benn CL, Soulet D et al: A novel pathogenic pathway of immune activation detectable before clinical onset in Huntington's disease. J Exp Med 2008, 205(8):1869-1877.

196. Ledo JH, Azevedo EP, Beckman D, Ribeiro FC, Santos LE, Razolli DS, Kincheski GC, Melo HM, Bellio M, Teixeira AL et al: Cross Talk Between Brain Innate Immunity and Serotonin Signaling Underlies Depressive-Like Behavior Induced by Alzheimer's Amyloid-beta Oligomers in Mice. J Neurosci 2016, 36(48):12106-12116.

197. Paresce DM, Ghosh RN, Maxfield FR: Microglial cells internalize aggregates of the Alzheimer's disease amyloid beta-protein via a scavenger receptor. Neuron 1996, 17(3):553-565.

198. Minagar A, Shapshak P, Fujimura R, Ownby R, Heyes M, Eisdorfer C: The role of macrophage/microglia and astrocytes in the pathogenesis of three neurologic disorders: HIV-associated dementia, Alzheimer disease, and multiple sclerosis. $J$ Neurol Sci 2002, 202(1-2):13-23.

199. Harvey LD, Yin Y, Attarwala IY, Begum G, Deng J, Yan HQ, Dixon CE, Sun D: Administration of DHA Reduces Endoplasmic Reticulum Stress-Associated Inflammation and Alters Microglial or Macrophage Activation in Traumatic Brain Injury. ASN Neuro 2015, 7(6).

200. Hosoi T, Honda M, Oba T, Ozawa K: ER stress upregulated PGE $2 /$ IFN $\gamma$-induced IL-6 expression and down-regulated iNOS expression in glial cells. Sci Rep 2013, 3:3388.

201. Hu P, Han Z, Couvillon A, Kaufman R, Exton J: Autocrine tumor necrosis factor alpha links endoplasmic reticulum stress to the membrane death receptor pathway through IRE1alpha-mediated NF-kappaB activation and down-regulation of TRAF2 expression. Mol Cell Biol 2006, 26(8):3071-3084.

202. Guthrie LN, Abiraman K, Plyler ES, Sprenkle NT, Gibson SA, McFarland BC, Rajbhandari R, Rowse AL, Benveniste EN, Meares GP: Attenuation of PKR-like ER Kinase (PERK) Signaling Selectively Controls Endoplasmic Reticulum Stress- 
induced Inflammation Without Compromising Immunological Responses. $J$ Biol Chem 2016, 291(30):15830-15840.

203. Halliday M, Radford H, Sekine Y, Moreno J, Verity N, le Quesne J, Ortori CA, Barrett DA, Fromont C, Fischer PM et al: Partial restoration of protein synthesis rates by the small molecule ISRIB prevents neurodegeneration without pancreatic toxicity. Cell death \& disease 2015, 6:e1672.

204. Moreno JA, Halliday M, Molloy C, Radford H, Verity N, Axten JM, Ortori CA, Willis AE, Fischer PM, Barrett DA et al: Oral Treatment Targeting the Unfolded Protein Response Prevents Neurodegeneration and Clinical Disease in Prion-Infected Mice. Sci Transl Med 2013, 5(206):206ra138.

205. Logsdon AF, Lucke-Wold BP, Nguyen L, Matsumoto RR, Turner RC, Rosen CL, Huber JD: Salubrinal reduces oxidative stress, neuroinflammation and impulsive-like behavior in a rodent model of traumatic brain injury. Brain Res 2016, 1643:140-151. 


\section{Chapter 3: Methodology}

\subsection{Reagents}

TaqMan primers were purchased from Life Technologies. Ac-DEVD-AMC (N-AcetylAsp-Glu-Val-Asp-7-amido-4-Methylcoumarin) was purchased from BD Biociences. Antibody

(Ab) for XBP1 was from Abcam. Ab for GAPDH was from EMD Millipore Corp. Abs for JNK and P-JNK were from Cell Signaling Technology. Abs for ATF4, CHOP and GRP78 were from Santa Cruz Biotechnology, Inc. Thapsigargin (Thaps) and tunicamycin were from Calbiochem. Dulbecco’s modified Eagle’s medium (DMEM), fetal bovine serum (FBS), HEPES, nonessential amino acids, L-glutamine, and penicillin-streptomycin were from Cellgro. Nonessential amino acids and gentamicin were from Lonza. Proteinase K was purchased from Promega. The Pierce Lactate Dehydrogenase (LDH) Cytoxicity Assay Kit was purchased from ThermoFisher Scientific. The terminal deoxynucleotidyl transferase dUTP nick-end labeling (TUNEL) assay was purchased from Trevige. B-27 serum-free supplement (50X) liquid was obtained from ThermoFisher Scientific.

\subsection{Mice and Primary Cell Preparations}

C57BL/6 mice were bred and housed in the animal facility at West Virginia University under the care of the animal resources program. Primary murine astrocyte cultures were prepared as previously described [7]. Astrocytes were cultured in DMEM with 10\% FBS, 16 mM HEPES, $1 \mathrm{x}$ nonessential amino acids, $2 \mathrm{mM}$ L-glutamine, 100 units/ml penicillin, $100 \mu \mathrm{g} / \mathrm{ml}$ streptomycin, and $50 \mu \mathrm{g} / \mathrm{ml}$ gentamicin. Astrocytes were separated from microglia by shaking at 200 rpm for 2 h. 


\subsection{Conditioned Media}

Primary murine astrocyte cultures were treated with $1.0 \mu \mathrm{M}$ Thaps for $2 \mathrm{~h}$. Cells were washed with Dulbecco's phosphate-buffered saline (PBS), and then incubated in fresh DMEM media for $24 \mathrm{~h}$. Conditioned media was centrifuged at 1,600 rpm for $10 \mathrm{~min}$ to pellet cellular debris. Media was collected and used for conditioned media experiments. Untreated cells concomitantly underwent the procedure. The vehicle (control) was treated with DMSO.

\subsection{Immunoblotting Analysis}

Cells were washed twice with PBS and lysed with immunoprecipitation (IP) lysis buffer (20 mM Tris [pH 7.5], $150 \mathrm{mM} \mathrm{NaCl,} 2$ mM EDTA, 2 mM EGTA, 0.5\% NP-40, and 1 x phosphatase/protease inhibitor cocktail [Pierce, Rockford, IL]). Protein concentrations were determined using the bicinchonicic acid assay (BCA) assay (Pierce, Rockford, IL). Equal amounts of protein from each sample were solubilized in Laemmli sample buffer (2\% SDS) and heated for $5 \mathrm{~min}$ at $95^{\circ} \mathrm{C}$. Proteins were separated by SDS-polyacrylamide gel electrophoresis and transferred to nitrocellulose, and the membranes were blocked in 5\% milk followed by an overnight incubation at $4^{\circ} \mathrm{C}$ with primary $\mathrm{Ab}$ diluted in $5 \%$ bovine serum albumin (BSA) or milk, according to the manufacturer's recommendation. Horseradish peroxidase-conjugated donkey anti-rabbit or donkey anti-mouse (1:2,000 dilution) secondary Ab was incubated for $1 \mathrm{~h}$ at room temperature, followed by detection with enhanced chemiluminescence.

\subsection{Reverse Transcription-quantitative Polymerase Chain Reaction (qRT-PCR)}

RNA was isolated using TRIzol (Fisher). RNA was quantified using a NanoDrop system (Fisher). One microgram of RNA was used for cDNA synthesis using Moloney murine leukemia virus (MMLV) reverse transcriptase (Promega). The cDNA was analyzed by quantitative PCR 
performed using TaqMan gene expression assays using Agilent Stratagene Mx3005P software. Reactions were carried out in $20 \mu \mathrm{l}$ and analyzed using the threshold cycle ( $\Delta \Delta \mathrm{CT})$ method.

\subsection{Determining Cell Viability}

\subsubsection{Caspase-3 Activity Assay}

Cleaved caspase-3 assay was carried out according to the manufacturer's instructions using the caspase-3 substrate Ac-DEVD-AMC. Briefly, cells were incubated with $200 \mu \mathrm{L}$ of buffer [final concentrations in 3x buffer: $150 \mathrm{mM}$ HEPES, $450 \mathrm{mM} \mathrm{NaCl}, 150 \mathrm{mM} \mathrm{KCl}, 30 \mathrm{mM} \mathrm{MgCl} 2,1.5 \%$ NP-40 alternative, $1.2 \mathrm{mM}$ ethylene glycol-bis( $\beta$-aminoethyl ether)-N,N,N',N'-tetraacetic acid (EGTA), $0.03 \%$ 3-[(3-cholamidopropyl)dimethylammonio-1-propanessulonate (CHAPS), and 30\% sucrose, $1.5 \mathrm{mM}$ of the fluorogenic substrate Ac-DEVD-AMC, $1 \mathrm{M}$ Dithiothreitol (DTT) and $100 \mathrm{mM}$ Phenylmethysulfonyl (PMSF)] following treatment. After incubation at $37^{\circ} \mathrm{C}$ for $1 \mathrm{~h}$, the release of AMC was measured with excitation at $360 \mathrm{~nm}$ and emission at $460 \mathrm{~nm}$ using fluorescence spectrophotometry.

\subsubsection{LDH Assay}

The LDH assay was carried out according to the manufacturer's instructions and as describe previously [2]. In brief, $50 \mu \mathrm{L}$ supernatant from cells treated with the indicated compounds/conditioned media and $50 \mathrm{uL}$ of reaction mixture (Substrate mix and Assay Buffer) was transferred to one well in a 96-well plate. Following incubation at room temperature for 30 min, 50 uL stop solution was added to each well. Extracellular LDH in the media was quantified by measuring the absorbance of released formazan dye at $490 \mathrm{~nm}$ with a subtraction wavelength of $680 \mathrm{~nm}$. Relative LDH activity was calculated using the following equation:

Treatment LDH activity (UT/Treatment) / maximal LDH activity (UT/Treatment) 


\subsubsection{TUNEL Assay}

The TUNEL assay was carried out on cells in monolayer using the protocol provided by the TACS ${ }^{\circledR} 2$ TdT Fluorescein kit (Trevige). In brief, cells were fixed on coverslips using $4 \%$ paraformaldehyde following the indicated treatment. After treatment with Proteinase K solution, the sample was immersed in Labeling Reaction Mix for $1 \mathrm{~h}$ in a humidified chamber. The reaction was halted by immersing samples with $1 \mathrm{X}$ TdT Stop Buffer at room temperature. Samples were covered with Strep-Fluor solution for 20 min in the dark, then viewed under a fluorescence microscope. TUNEL positive cells were counted. DAPI was used to label nuclei.

\subsection{Microparticle Isolation by Ultracentrifugation}

Conditioned media was collected from cells and centrifuged at $1,600 \mathrm{x}$ g at $4^{\circ} \mathrm{C}$ for 5 minutes to remove cellular debris. The centrifuged conditioned media was collected separately from the pellet and used for ultracentrifugation. Samples were spun at $160,000 \mathrm{x}$ g at $4^{\circ} \mathrm{C}$ for $1 \mathrm{~h}$ using Nalgene Oak Ridge conical tubes (Thermo Fisher Scientific). Conditioned media was collected and the pellet was reconstituted in Dulbecco's PBS. Both the ultracentrifuged media and microparticale-containing solution was used for the conditioned media experiments.

\subsection{Treatment of Conditioned Media with Proteinase K}

Proteinase K (Promega), which contained proteinase K enzyme covalently attached to agarose beads, was used to digest protein molecules within the conditioned media. In brief, a 1.5 $\mathrm{mL}$ tube containing $1 \mathrm{~mL}$ B-27 supplemented media serum-free conditioned media and $100 \mu \mathrm{L}$ proteinase K slurry (proteinase $\mathrm{K}+\mathrm{PBS}$ ) incubated in a $37^{\circ} \mathrm{C}$ thermocycler at $500 \mathrm{rpm}$ for $1 \mathrm{~h}$. Samples were then centrifuged at 2,000 x g for 2 min to pellet the agarose, and thus the proteinase 
K enzyme. The proteinase K-treated conditioned media was incubated with the indicated receiver cells to determine if the ER stress-inducing stress factor was a protein.

\subsection{Statistical Analysis}

Statistical differences between experimental groups were determined using the software program GraphPad Prism. One-way ANOVA was used to determine statistically significant differences between the means of three or more independent groups. Two-way ANOVA was used to determine statistically significant differences between groups with more than one independent variable. All data are shown as means \pm standard error. $\mathrm{p}<0.05$ was considered statistically significant. 


\subsection{References}

1. Meares GP, Liu Y, Rajbhandari R, Qin H, Nozell SE, Mobley JA, Corbett JA, Benveniste EN: PERK-Dependent Activation of JAK1 and STAT3 Contributes to Endoplasmic Reticulum Stress-Induced Inflammation. Mol Cell Biol 2014, 34(20):3911-3925.

2. Korzeniewski C, Callewaert DM: An enzyme-release assay for natural cytotoxicity. $J$ Immunol Methods 1983, 64(3):313-320. 


\section{Chapter 4: Results}

\subsection{ER stress is Transmissible among Cells of the CNS in vitro.}

We recently demonstrated that ER stressed astrocytes can upregulate inflammatory gene expression in microglia [1]. Because it has been shown that transmissible ER stress maybe a relevant phenomenon in cancer [2], we investigated whether ER stress generated in astrocytes could trigger the secretion of molecules which, in turn, regulate ER stress responses in unstressed CNS cells. To do this, we produced, then transferred ER stressed ACM to unstressed astrocytes and neurons. As described in Figure 1A, astrocytes were stimulated with the ER stress-inducing agent Thaps, a non-competitive inhibitor of the sarco/endoplasmic reticulum $\mathrm{Ca}^{2+}$ ATPase (SERCA) [3], for $2 \mathrm{~h}$ to induce transient ER stress. The ability of Thaps to induce ER stress in astrocytes has been shown in previous studies [1, 4]. We followed the treatment with a $24 \mathrm{~h}$ wash out period with fresh media. This step is critical as any mediator secreted from ER stressed astrocytes would be collected in the media without the presence of Thaps. Therefore, we could determine whether ER stressed astrocytes could modulate ER stress responses in unstressed cells through a paracrine mechanism by incubating different receiver cells with the conditioned media. No difference in lactate dehydrogenase (LDH) activity was detected in the conditioned media, indicating that the secretory profile of the astrocytes during the washout period was not a product of cell death (Figure 1A). This finding is consistent with our previous observations that astrocyte viability was not compromised when stimulated with various concentrations of Thaps for $24 \mathrm{~h}$ [1]. Importantly, a previous study using an identical procedure detected no carry over Thaps when analyzing the conditioned media of ER stressed cells using mass spectroscopy [2]. 
To determine if ER stress could initiate the secretion of ER stress-inducing molecules from astrocytes, we incubated primary murine astrocytes and the murine HT-22 neuronal cell line with ER stressed ACM for $6 \mathrm{~h}$. The contents within the ER stressed ACM significantly upregulated the expression of downstream signaling components associated with all three arms of the UPR relative to cells incubated with control ACM (Figure 1B-C). We performed a similar experiment using ER stressed ACM derived from astrocytes stimulated with tunicamycin (Tunic), an Nglycosylation inhibitor. The use of another ER stress-inducing agent was important because it would show that ER stress transmission could be initiated by multiple insults which promote ER stress. Similar to our findings using Thaps, ER stressed ACM from Tunic-treated astrocytes increased ATF4, CHOP and GRP78 protein expression in HT-22 neurons, albeit after $18 \mathrm{~h}$ (Figure 1D). Based on our previous observations, treating astrocytes with Tunic for $>2 \mathrm{~h}$ does not reduce cell viability [1]. It appears that ER stressed ACM from Tunic-treated astrocytes is not as potent as media from Thaps-treated astrocytes, possibly due to the differential mechanism of action between the two pharmacological agents.

Consistent with our previous findings that ER stressed astrocytes promote inflammatory signaling in microglia without the need for cell-to-cell contact [1], we show that ER stressed ACM induces the expression of IL-6, CCL2 and CCL20 mRNA in other astrocytes (Figure 2). Pretreating receiver astrocytes with TUDCA, a chemical chaperone known to alleviate ER stress, partly reduces the transcription of genes encoding these signaling proteins (Figure 2). This finding implies that ER stressed astrocytes are secreting mediators which promote ER stress-dependent and -independent inflammatory signaling in receiver astrocytes.

\subsection{ER Stressed Astrocytes initially Protect Neurons against Subsequent Stress}


In addition to mediating inflammatory and ER stress responses, we wanted to determine whether ER stressed astrocytes were able to confer stress resistance to neurons. HT-22 neurons exposed to ER stressed ACM for $24 \mathrm{~h}$ succumb to apoptosis (Figure 3A-C). No differences in caspase-3 activity were observed between the groups incubated with ER stressed ACM relative to the control after $6 \mathrm{~h}$, indicating that the factor(s) within the ACM became cytotoxic to neurons after $6 \mathrm{~h}$ (Figure 3A). Next, we sought to identify the conditions necessary for ER stressed ACM to induce a hormetic response in neurons. We chose to follow the accepted model proposing that the lowlevel activation of the ER stress sensors promotes an adaptive state by selectively upregulating the expression of pro-survival proteins, without the concomitant expression of UPR-associated apoptotic factors [5]. To this point, we set our preconditioning standards where neurons highly expressed chaperone proteins (GRP78, pro-survival [6]) and do not express CHOP, which is considered apoptotic [7-9].

As shown in Figure 1C and 3C, stimulating HT-22 neurons with ER stressed ACM for $6 \mathrm{~h}$ increases the protein expression of GRP78 and CHOP. Following a $24 \mathrm{~h}$ washout period, GRP78 protein expression was maintained, while CHOP protein expression dissipated, consistent with the short half-life of CHOP [10] (Figure 3D). Although stimulating neurons for $2 \mathrm{~h}$ with ER stressed ACM, followed with a $4 \mathrm{~h}$ washout period achieves a preconditioned state, the expression of GRP78 is significantly reduced after $24 \mathrm{~h}$ (Figure 3D). This would suggest that the adapted state induced under these conditions is not as established compared to when neurons are stimulated for $6 \mathrm{~h}$, then allowed to recover for $24 \mathrm{~h}$. Therefore, we used these conditions to determine whether preconditioning neurons promotes resistance against ER stress-induced cell death.

We stimulated preconditioned neurons with Thaps for the indicated time points and analyzed the protein expression of phosphorylated JNK (P-JNK) and CHOP, pro-apoptotic factors induced 
during UPR-mediated apoptosis [11] (Figure 4A-B). Additionally, we assessed caspase-3 activity in preconditioned neurons after Thaps treatment (Figure 4C). Pretreating neurons with ER stressed ACM attenuates total P-JNK, both basally and when neurons were stimulated with Thaps for $4 \mathrm{~h}$ (Figure 4A). Furthermore, we found that neurons preconditioned with ER stressed ACM exhibit less caspase-3 activity after a 4 treatment with Thaps (Figure 4C). This preconditioning effect diminished when neurons were stimulated with Thaps for 18 h, as ER stressed ACM-conditioned neurons had a similar expression of both CHOP and P-JNK relative to the controls (Figure 4B). Moreover, basal GRP78 levels were significantly reduced after $18 \mathrm{~h}$, indicating that the preconditioned state was not maintained $42 \mathrm{~h}(24 \mathrm{~h}+18 \mathrm{~h})$ after being exposed to ER stressed ACM (Figure 4B). Interestingly, caspase-3 activity was still reduced in neurons preconditioned with ER stressed ACM after being stimulated with Thaps for $18 \mathrm{~h}$ (Figure 4C). We expect that caspase-3 activity in the preconditioned group would be closer to control levels if we had extended the Thaps treatment beyond $18 \mathrm{~h}$. Taken together, these data indicate that ER stressed astrocytes initially confer stress resistance to neurons by engaging the adaptive mechanisms of the UPR to promote hormesis. Nevertheless, this protective effect is lost after prolonged cell-nonautonomous ER stress.

\subsection{The Secreted Stress Factor(s) is not a Microparticle, and Resistant to Proteinase K}

Finally, we wanted to characterize the molecular determinant(s) secreted from ER stressed astrocytes that evoked ER stress responses in receiver cells. To exclude the possibility that the inflammatory cytokines secreted by activated astrocytes were responsible for inducing ER stress in neurons, we stimulated neurons with IL-6 for $6 \mathrm{~h}$ (Figure 5A). IL-6 is major pro-inflammatory cytokine secreted by ER stressed astrocytes [4], and it is well known that IL-6-driven inflammatory responses contribute to disease-associated inflammation [12]. In addition to IL-6, we also 
stimulated neurons with IL-1 $\beta$ and TNF $\alpha$, both of which are considered main effectors in the development of pathological neuroinflammation (Figure 5A) [13, 14]. Contrary to previous findings with hepatocytes [15], IL-6, IL-1 $\beta$ or TNF $\alpha$ did not induce ER stress in neurons after $6 \mathrm{~h}$ in vitro, even when using a physiologically high concentration $(10 \mathrm{ng} / \mathrm{mL})$ (Figure 5A). This finding supports a previous observation where transmissible ER stress between tumor cells and macrophages did not involve the IL-6 receptor [2]. Moreover, toll-like receptor 2 and 4 also appear to be indispensable in this phenomenon $[2,16]$.

Extracellular vesicle secretion provides a means of transcellular communication in the CNS and is essential for the interactive exchanges of cargo that maintain neuronal competency [17]. Under conditions of neurodegeneration, however, toxic substrates can potentially be incorporated into extracellular vesicles and perturb CNS homeostasis [18]. To determine whether microparticles (MP) were responsible for inducing ER stress in receiver cells, we isolated MPs from the ER stressed ACM using ultracentrifugation. Unstressed astrocytes incubated with MP-free ER stressed ACM showed a similar magnitude of induction in the transcription of ATF4, CHOP and GRP78 mRNA compared to astrocytes incubated with ER stressed ACM (Figure 5B). In contrast, astrocytes stimulated with the MP-containing solution did not show any signs of UPR activation (Figure 5B). These findings indicated that the extracellular vesicles in the conditioned media were not the stress factor(s) responsible for inducing ER stress in astrocytes or neurons.

Next, we pretreated ER stressed ACM with proteinase K to digest the protein molecules within the sample. If the ACM failed to induce ER stress in receiver cells following proteinase K treatment, this would indicate that the secreted stress factor(s) is a protein. We show that proteinase K-treated ER stressed ACM still induces CHOP and GRP78 gene transcription, suggesting that the stress 
factor(s) responsible for inducing cell-nonautonomous UPR activation is not resistant to proteinase K digestion (Figure 5C). 


\subsection{Figure Legend}

Figure 1. ER stressed astrocytes secrete molecules which upregulate ER stress responses in multiple receiver cell types. (A) Outline for the astrocyte conditioned media (ACM) experiments. Following treatment with the vehicle (DMSO) or $1.0 \mu \mathrm{M}$ thapsigargin (Thaps) for $2 \mathrm{~h}$, primary murine astrocyte cultures were washed with PBS three times, then allowed to incubate in fresh media for $24 \mathrm{~h}$. After this period, the media (ACM) was collected. Lactate dehydrogenase (LDH) activity in the collected ACM was measured using the LDH assay. (B-C) Primary murine astrocytes (B) and murine HT-22 hippocampal neurons (C) incubated with control (UT ACM) or ER stressed ACM (Thaps ACM) for 6 h. CHOP and GRP78 mRNA expression was quantified using RT-qPCR. Immunoblot analysis was used to examine GRP78, spliced XBP-1 (sXBP-1) and CHOP protein expression. $1.0 \mu \mathrm{M}$ (B) or $0.1 \mu \mathrm{M}$ (C) Thaps was used as the positive control for B and C, respectively. GAPDH was used as the loading control. (D) HT-22 neurons incubated with control or ER stressed ACM from tunicamycin (Tunic)-treated primary murine astrocytes for the indicated time points. Immunoblot analysis was used to examine GRP78, ATF4 and CHOP protein expression. GAPDH was used as the loading control. All values are mean \pm SE. n.s., not significant $\mathrm{P}>0.05 ; *, \mathrm{P} \leq 0.05 ; * *, \mathrm{P} \leq 0.001 ; * * *, \mathrm{P} \leq 0.0001 ; * * * *, \mathrm{P} \leq 0.00001$

\section{Figure 2. Cell-nonautonomous ER stress promotes inflammatory signaling in astrocytes.} Astrocytes were pretreated with the chemical chaperone TUDCA (500 $\mu \mathrm{M})$ for $24 \mathrm{~h}$ prior to incubating with control or ER stressed astrocyte conditioned media (UT or Thaps ACM) for 6 h. IL-6, CCL2 and CCL20 mRNA expression was quantified using RT-qPCR. All values are mean \pm SE. n.s., not significant $\mathrm{P}>0.05 ; *, \mathrm{P} \leq 0.05 ; * *, \mathrm{P} \leq 0.001 ; * * *, \mathrm{P} \leq 0.0001 ; * * * *, \mathrm{P} \leq 0.00001$. 
Figure 3. Mild exposure to stress factors promotes an adaptive state in neurons. (A) Murine HT-22 hippocampal neurons were stimulated with control or ER stressed astrocyte conditioned media (UT or Thaps ACM) for 6 or 24 h. Caspase-3 activity was assessed by measuring the fluorescence intensity of the cleaved capase-3 substrate Ac-DEVD-AMC. Caspase-3 activity was expressed as arbitrary fluorescence units. (B) Immunoblot analysis was used to examine cleaved caspase-3 and caspase-3 protein expression in HT-22 neurons stimulated with control or ER stressed conditioned media for the indicated time points. (C) The TUNEL assay was utilized to label 3'-OH termini of double-stranded DNA breaks in neurons treated with control (UTA) or ER stressed ACM (TA) for 24 h. Strand breaks were visualized using fluorescence microscopy. (D) HT-22 neurons incubated with 25\% control or ER stressed ACM for the indicated time points. GRP78 and CHOP protein expression was examined using immunoblot analysis. (E) HT-22 neurons incubated with 25\% control or ER stressed ACM for 2 or 6 h, followed with a 4 or 24 h washout period. GRP78 and CHOP protein expression was examined using immunoblot analysis. GAPDH was used as the loading control (D-E). UT, untreated; UTA, control ACM; TA, Thaps ACM. All values are mean \pm SE. n.s., not significant $\mathrm{P}>0.05 ; *, \mathrm{P} \leq 0.05 ; * *, \mathrm{P} \leq 0.001 ; * * *, \mathrm{P}$ $\leq 0.0001 ; * * * *, \mathrm{P} \leq 0.00001$.

Figure 4. Conditioned media from ER stressed astrocytes confer stress resistance to neurons. Murine HT-22 hippocampal neurons were preconditioned with 25\% control (UTA or UT ACM) or ER stressed ACM (TA or Thaps ACM) for 6 h, followed by a 24 h recovery period with fresh media. (A-B) GRP78, phosphorylated JNK (P-JNK) and CHOP protein expression was assessed using immunoblot analysis. GAPDH was used as the loading control. Data are a representation of three independent experiments. (C) Caspase-3 activity was analyzed by measuring the 
fluorescence intensity of the cleaved caspase-3 substrate Ac-DEVD-AMC after preconditioned HT-22 neurons were stimulated with either the vehicle (DMSO) or $0.1 \mu \mathrm{M}$ thapsigargin (Thaps) for $4 \mathrm{~h}$ or $18 \mathrm{~h}$. Caspase-3 activity was expressed as arbitrary fluorescence units. All values are mean \pm SE. n.s., not significant $\mathrm{P}>0.05 ; *, \mathrm{P} \leq 0.05 ; * *, \mathrm{P} \leq 0.001 ; * * *, \mathrm{P} \leq 0.0001 ; * * * *, \mathrm{P} \leq$ 0.00001 .

Figure 5. The stress factor(s) secreted by ER stressed astrocytes is not microparticle, and is resistant to proteinase K. (A) Murine HT-22 hippocampal neurons were stimulated with 10 ng/mL of IL-1 $\beta$, IL-6 or TNF $\alpha$ for $6 \mathrm{~h}$. CHOP and GRP78 mRNA expression was quantified using RT-qPCR. Thaps $(1 \mu \mathrm{M})$ was used as a positive control. (B) Microparticles (MP) were isolated from the ER stressed astrocyte conditioned media (ACM) via ultracentrifugation (160,000 x g for $1 \mathrm{~h})$. The MP-free ACM remaining after high-speed centrifugation was collected, and the pellet at the bottom of the tube (contains MPs) was resuspended in PBS. The centrifuged ACM (thapsigargin (Thaps) ACM No MP) and the solution containing the MPs (Thaps ACM MP) incubated with astrocytes for $6 \mathrm{~h}$. ATF4, CHOP and GRP78 mRNA was quantified using RT-qPCR. (C) ER stressed ACM was treated with proteinase K bound by agarose beads for $1 \mathrm{~h}$ at $37^{\circ} \mathrm{C}$. After which, the ACM was centrifuged at $1000 \mathrm{x}$ g for 2 min to separate the beads and the media. The proteinase K-free ACM was collected, then allowed to incubate with astrocytes for $4 \mathrm{~h}$. CHOP and GRP78 mRNA was quantified using RT-qPCR. To confirm that proteinase K was functional, 1 $\mathrm{mg} / \mathrm{mL}$ of BSA was treated with proteinase $\mathrm{K}$ for $1 \mathrm{~h}$ at $37^{\circ} \mathrm{C}$. Proteins from the BSA (lanes 1 and 2) or proteinase K-treated BSA (lanes 3 and 4) solutions were stained using Coomassie Blue staining following SDS-PAGE. All values are mean \pm SE. n.s., not significant $\mathrm{P}>0.05 ; *, \mathrm{P} \leq$ $0.05 ; * *, \mathrm{P} \leq 0.001 ; * * *, \mathrm{P} \leq 0.0001 ; * * * *, \mathrm{P} \leq 0.00001$. 
Figure 6. Schematic representing the cell-nonautonomous influence of ER stressed astrocytes based on our data. 


\subsection{Figures}

Figure 1
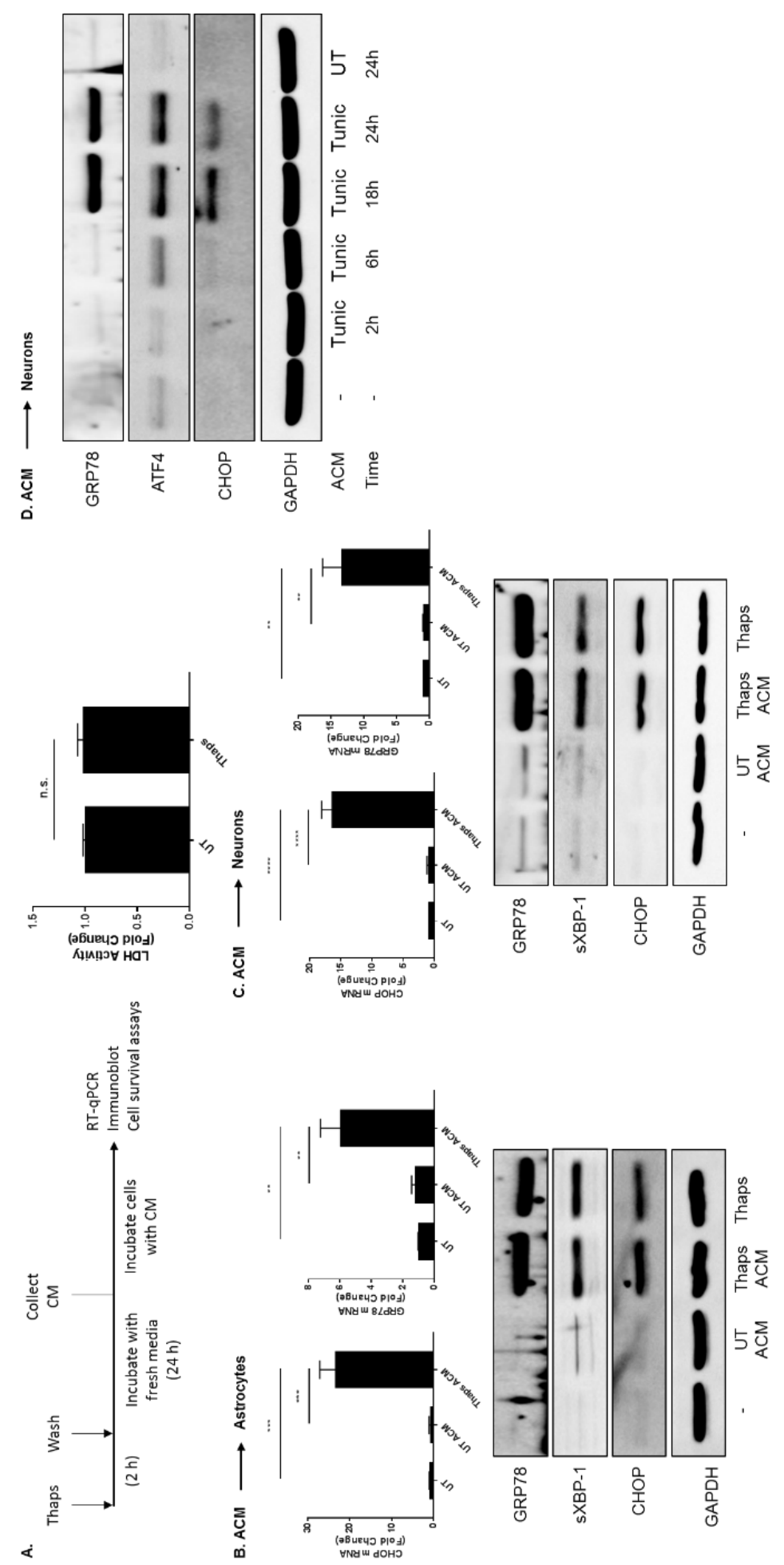
Figure 2
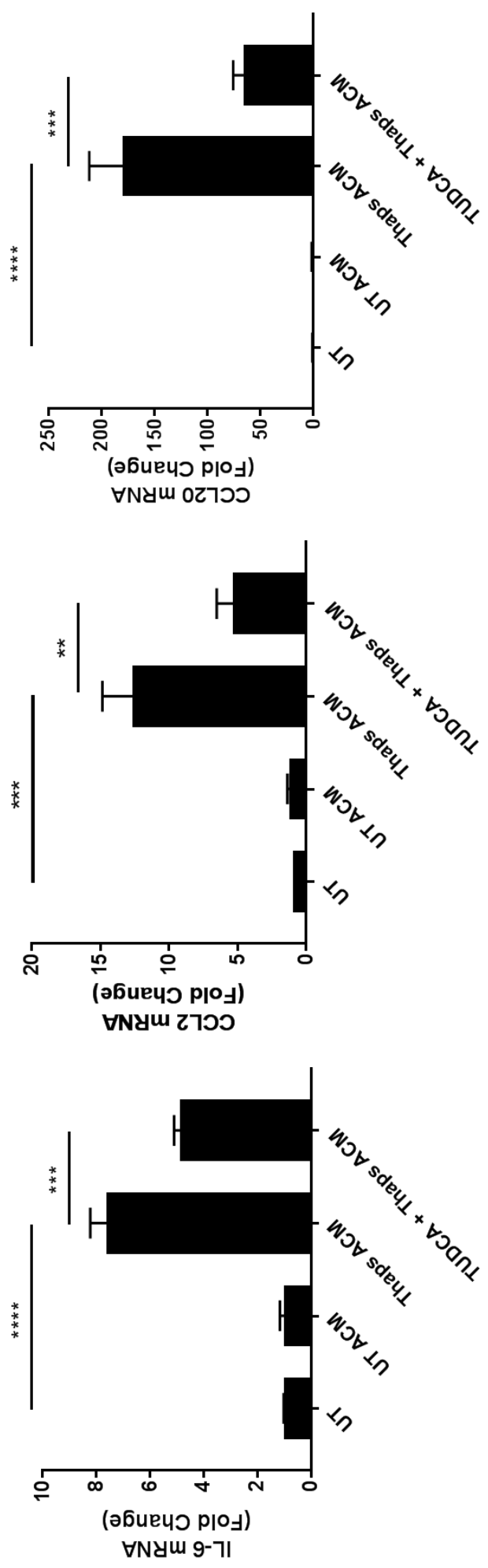
Figure 3

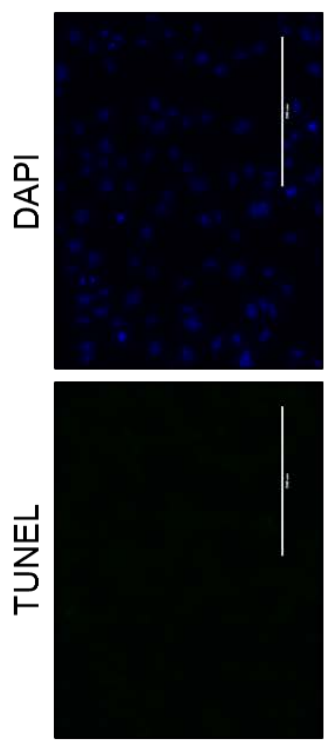

5

j
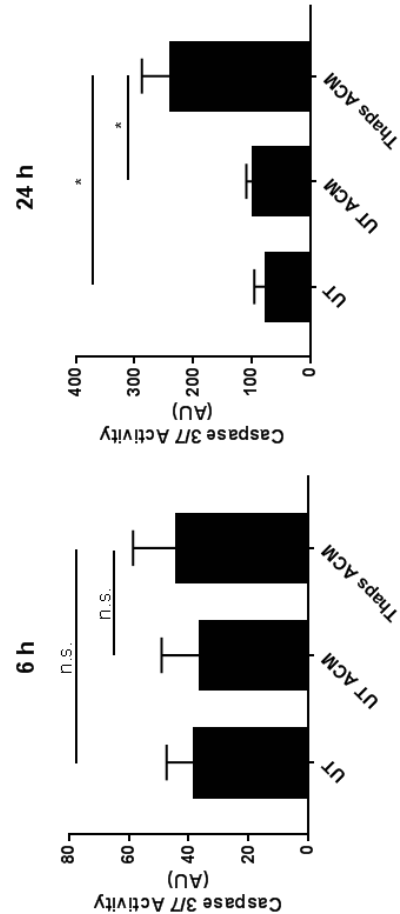

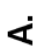
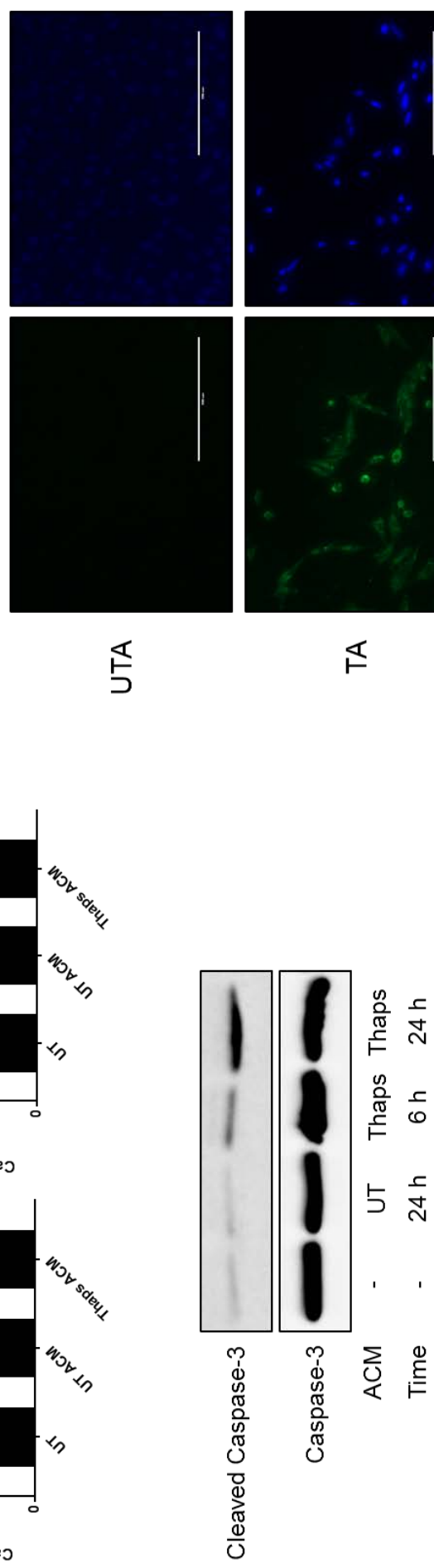

ต

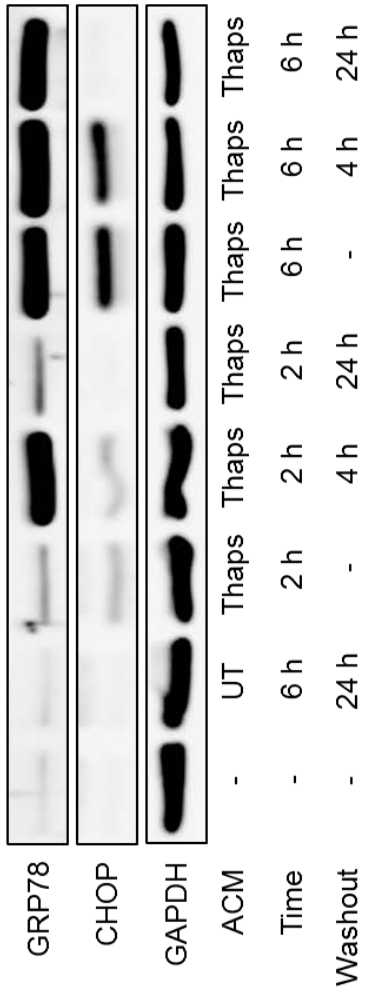

ய

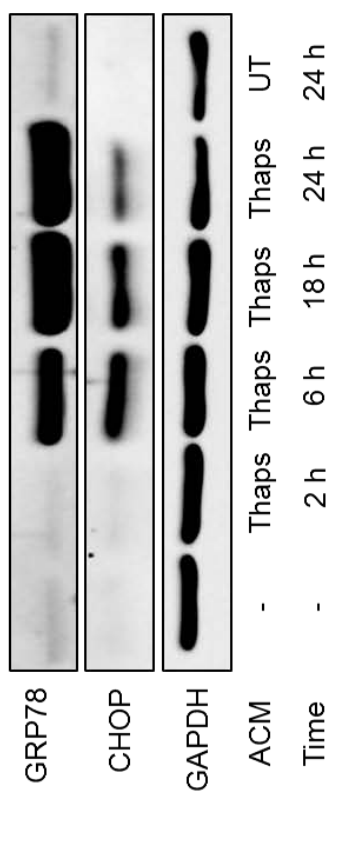


Figure 4

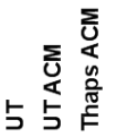

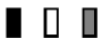

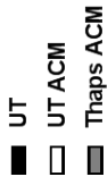
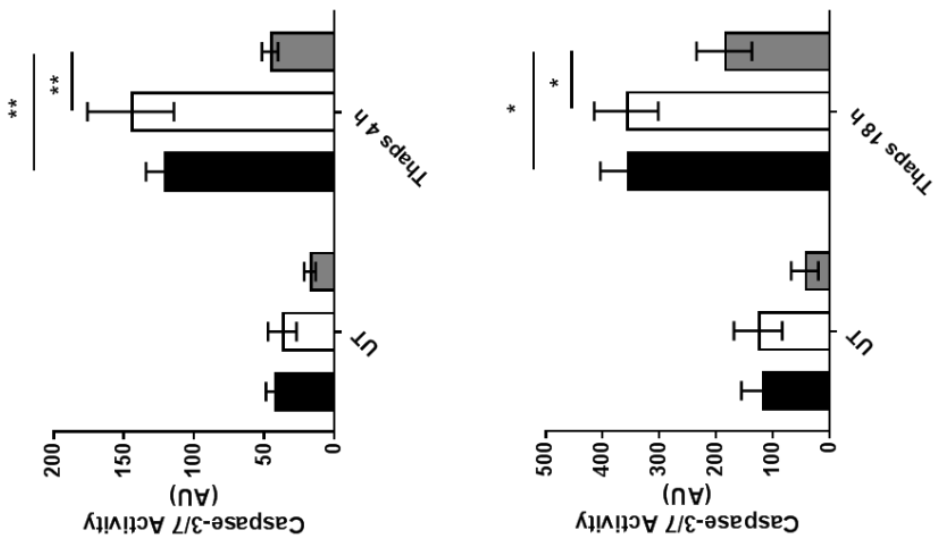

ن

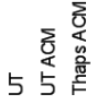

I 0 प

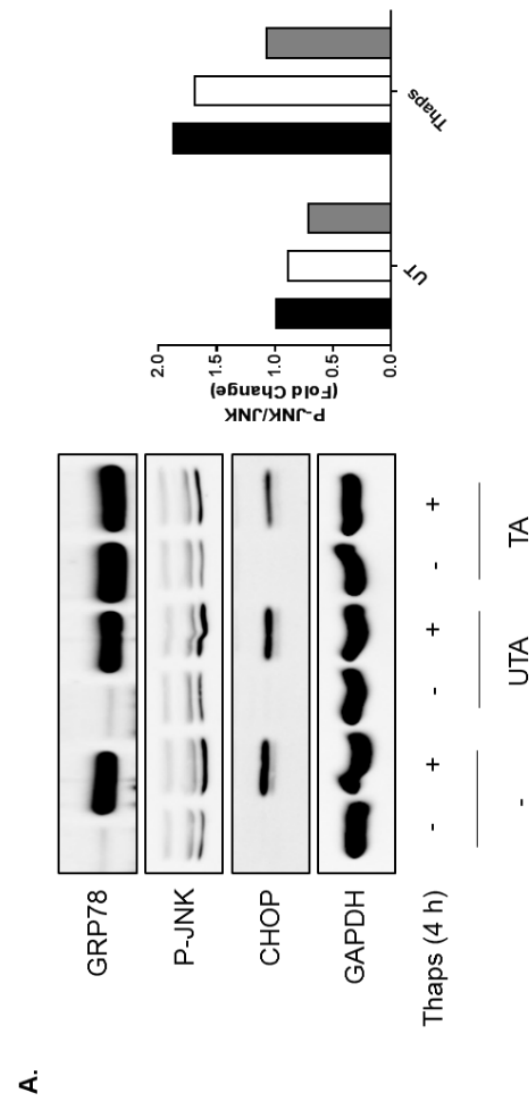

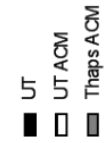
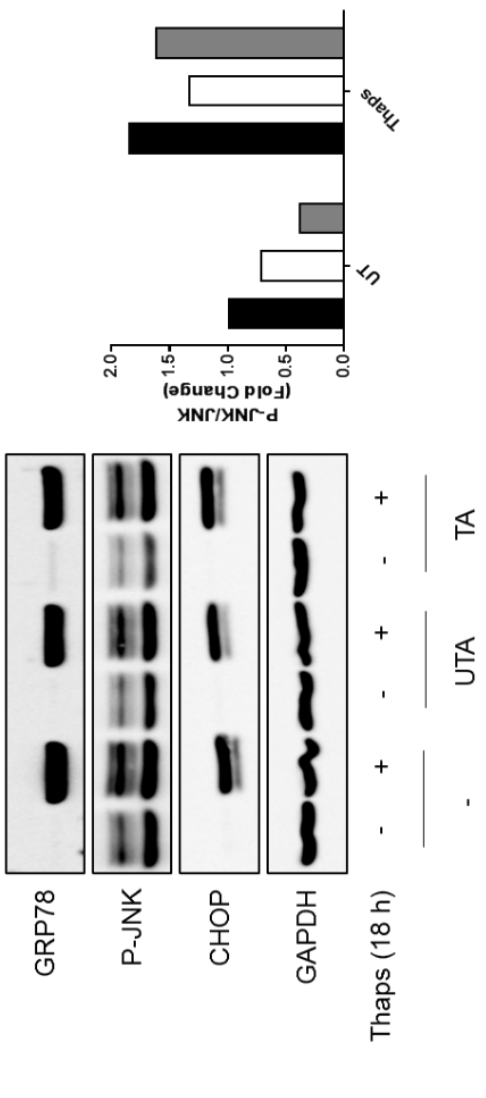
Figure 5

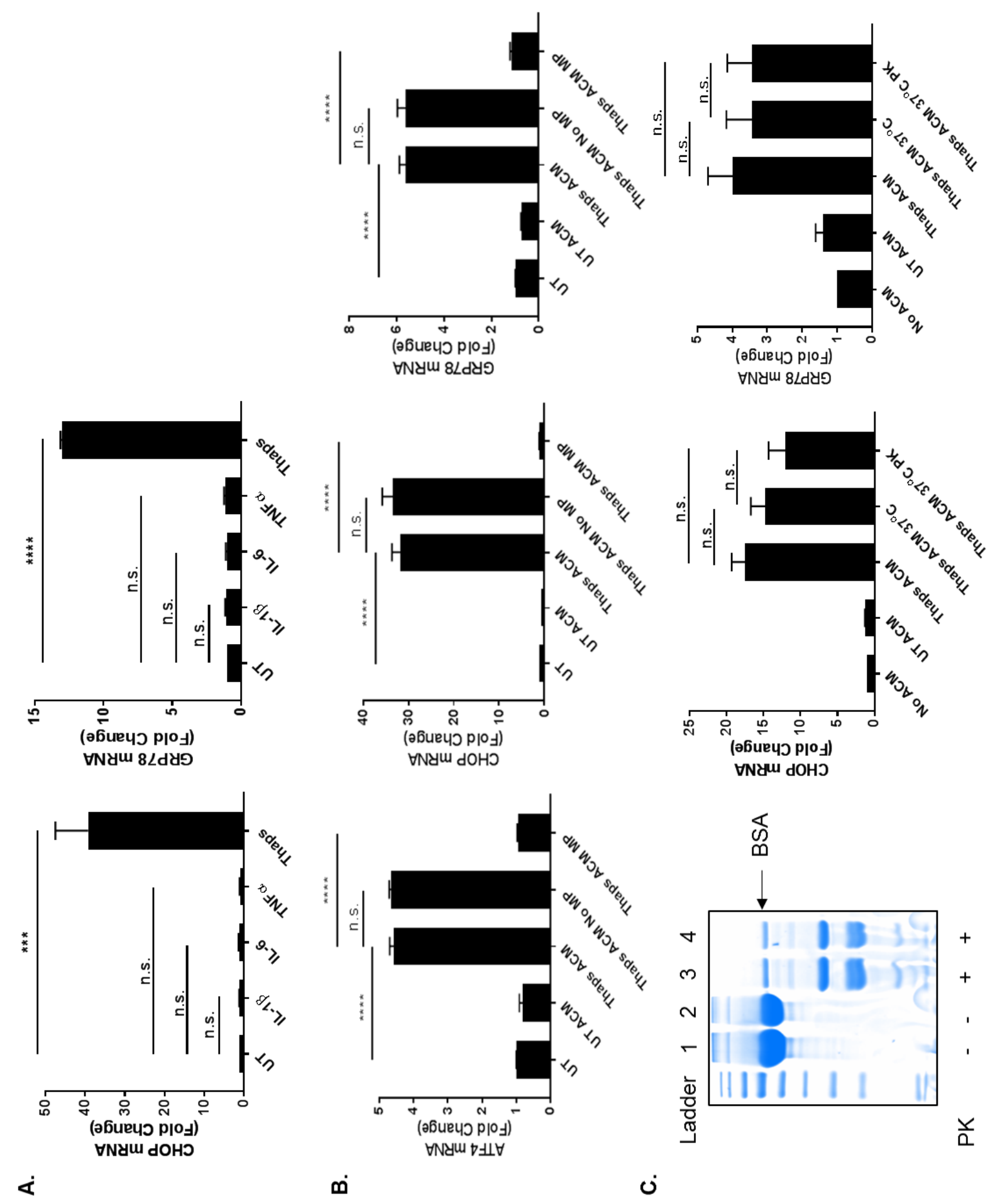


Figure 6
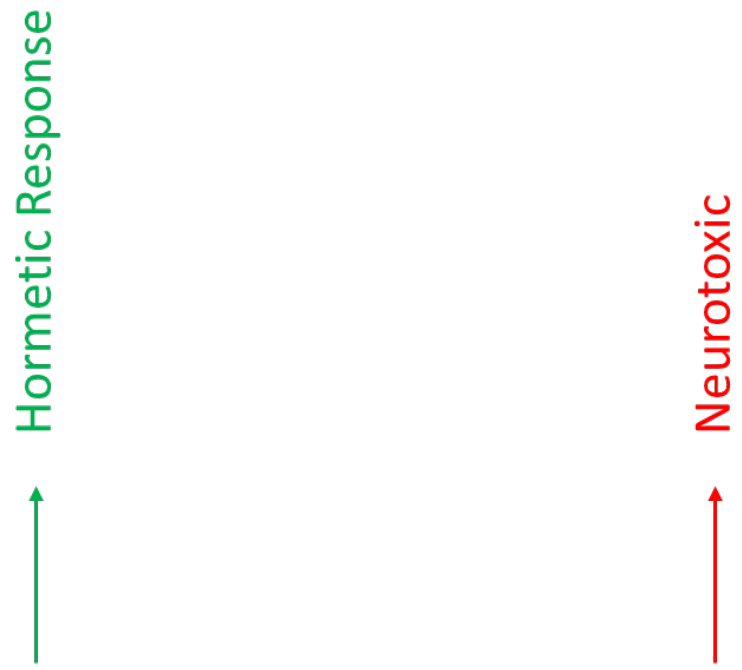

c
은
ป

동
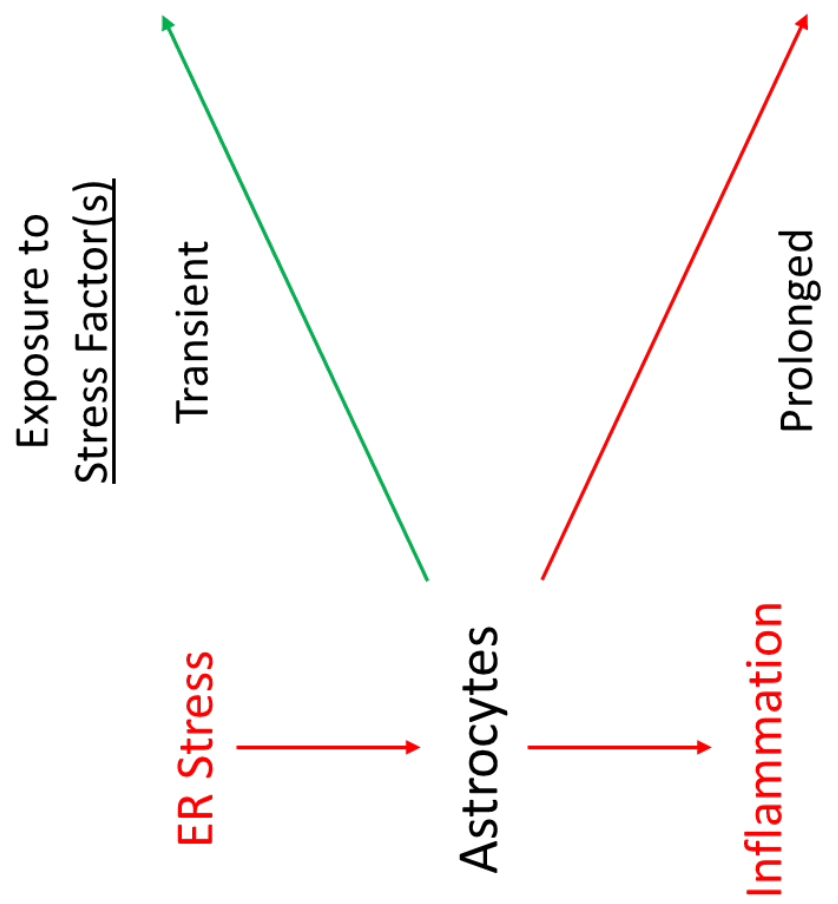


\subsection{References}

1. Meares GP, Liu Y, Rajbhandari R, Qin H, Nozell SE, Mobley JA, Corbett JA, Benveniste EN: PERK-Dependent Activation of JAK1 and STAT3 Contributes to Endoplasmic Reticulum Stress-Induced Inflammation. Mol Cell Biol 2014, 34(20):3911-3925.

2. Mahadevan NR, Rodvold J, Sepulveda H, Rossi S, Drew AF, Zanetti M: Transmission of endoplasmic reticulum stress and pro-inflammation from tumor cells to myeloid cells. Proc Natl Acad Sci U S A 2011, 108(16):6561-6566.

3. Lytton J, Westlin M, Hanley MR: Thapsigargin inhibits the sarcoplasmic or endoplasmic reticulum Ca-ATPase family of calcium pumps. J Biol Chem 1991, 266(26):17067-17071.

4. Guthrie LN, Abiraman K, Plyler ES, Sprenkle NT, Gibson SA, McFarland BC, Rajbhandari R, Rowse AL, Benveniste EN, Meares GP: Attenuation of PKR-like ER Kinase (PERK) Signaling Selectively Controls Endoplasmic Reticulum Stressinduced Inflammation Without Compromising Immunological Responses. $J$ Biol Chem 2016, 291(30):15830-15840.

5. Rutkowski D, Arnold S, Miller C, Wu J, Li J, Gunnison K, Mori K, Sadighi Akha A, Raden D, Kaufman R: Adaptation to ER stress is mediated by differential stabilities of pro-survival and pro-apoptotic mRNAs and proteins. PLoS Biol 2006, 4(11):e374.

6. Racek T, Buhlmann S, Rust F, Knoll S, Alla V, Putzer BM: Transcriptional repression of the prosurvival endoplasmic reticulum chaperone GRP78/BIP by E2F1. J Biol Chem 2008, 283(49):34305-34314.

7. Li Y, Guo Y, Tang J, Jiang J, Chen Z: New insights into the roles of CHOP-induced apoptosis in ER stress. Acta Biochim Biophys Sinica 2014, 46(8):629-640.

8. Marciniak SJ, Yun CY, Oyadomari S, Novoa I, Zhang Y, Jungreis R, Nagata K, Harding HP, Ron D: CHOP induces death by promoting protein synthesis and oxidation in the stressed endoplasmic reticulum. Genes Dev 2004, 18(24):3066-3077.

9. Song B, Scheuner D, Ron D, Pennathur S, Kaufman RJ: Chop deletion reduces oxidative stress, improves beta cell function, and promotes cell survival in multiple mouse models of diabetes. J Clin Invest 2008, 118(10):3378-3389.

10. Rutkowski DT, Arnold SM, Miller CN, Wu J, Li J, Gunnison KM, Mori K, Sadighi Akha AA, Raden D, Kaufman RJ: Adaptation to ER stress is mediated by differential stabilities of pro-survival and pro-apoptotic mRNAs and proteins. PLoS Biol 2006, 4(11):e374.

11. Tabas I, Ron D: Integrating the mechanisms of apoptosis induced by endoplasmic reticulum stress. Nat Cell Biol 2011, 13(3):184-190.

12. Gabay C: Interleukin-6 and chronic inflammation. Arthritis Res Ther 2006, 8 Suppl 2:S3.

13. Leal MC, Casabona JC, Puntel M, Pitossi FJ: Interleukin-1beta and tumor necrosis factor-alpha: reliable targets for protective therapies in Parkinson's Disease? Front Cell Neurosci 2013, 7:53.

14. Yuan L, Neufeld AH: Tumor necrosis factor-alpha: a potentially neurodestructive cytokine produced by glia in the human glaucomatous optic nerve head. Glia 2000, 32(1):42-50. 
15. Zhang K, Shen X, Wu J, Sakaki K, Saunders T, Rutkowski DT, Back SH, Kaufman RJ: Endoplasmic reticulum stress activates cleavage of CREBH to induce a systemic inflammatory response. Cell 2006, 124(3):587-599.

16. Zhang $\mathrm{H}$, Yue $\mathrm{Y}$, Sun $\mathrm{T}$, Wu X, Xiong S: Transmissible endoplasmic reticulum stress from myocardiocytes to macrophages is pivotal for the pathogenesis of CVB3induced viral myocarditis. Sci Rep 2017, 7:42162.

17. Budnik V, Ruiz-Cañada C, Wendler F: Extracellular vesicles round off communication in the nervous system. Nat Rev Neurosci 2016, 17(3):160-172.

18. Thompson AG, Gray E, Heman-Ackah SM, Mäger I, Talbot K, Andaloussi SE, Wood MJ, Turner MR: Extracellular vesicles in neurodegenerative disease - pathogenesis to biomarkers. Nat Rev Neurol 2016, 12(6):346-357. 


\section{Chapter 5: Discussion}

\subsection{Discussion}

Studies investigating how pathological UPR signaling contributes to neurodegenerative diseases have largely focused on neuronal cell-autonomous mechanisms. Nevertheless, there still remains a plethora of questions regarding the cell-nonautonomous role of the UPR under normal physiology, and how this mechanism is compromised in diseased states. To our knowledge, we provide the first evidence showing that ER stress is transmissible among mammalian CNS cells. The activation of the UPR has been shown to play an essential role in maintaining vital biological processes within the brain during cellular stress. In fact, moderate ER stress enhances cellular protection against subsequent ER stress-inducing stimuli by improving the adaptive capacity of the cell, a response called the hormetic response [1]. These observations led us to the thinking that transmissible ER stress could be essential for alerting surrounding cells about upcoming distresses, and to prepare them for subsequent insult by initiating the adaptive signals of the UPR. In support of this concept, direct activation of sXBP-1, a downstream transcription factor of the IRE-1 $\alpha$ pathway, in neurons has been shown to improve stress resistance in distal, non-neuronal cells by regulating UPR signaling components through the secretion of neurotransmitters in Caenorhabditis elegans [2]. In agreement with these findings, our data suggest that ER stressed astrocytes initially protect neurons by inducing mild, cell-nonautonomous ER stress, which in turn increases their resistance against sequential ER stress (Figure 4).

It is important to note that the cell-nonautonomous effects induced by Thaps may not necessarily be due to ER stress. To this point, Thaps administration significantly elevates the concentration of cytosolic calcium by impairing the transport of once ER-localized calcium back into the ER lumen 
[3]. High levels of cytosolic calcium, in turn, affects a number of biological processes. For example, high cytosolic concentrations of calcium can stimulate inflammatory gene expression [4] and facilitate mitochondrial damage [5, 6]. We must stress that decreases in ER calcium levels are not specific to Thaps treatment, but rather it is a common event that contributes to ER dysfunction [7] and is a consequence of abnormal UPR signaling [5, 8, 9]. In addition, alterations in the redox environment resulting from the enhanced generation of reactive oxygen species (ROS) during ER stress may profoundly disrupt many normal cellular activities [10]. Since perturbations in ER homeostasis affects a number of processes involved in cellular physiology, it should be considered that disturbances in other aspects of cell biology caused by the ER stress response may promote the secretion of this unknown molecule(s). Further, the use of Tunic, an inhibitor of Nacetylglucosamine phosphotransferase that abrogates N-glycoslyation, was essential in supporting that our results using Thaps as an ER stress-inducing agent was not simply a product of any of its off-target effects (Figure 1D).

A number of CNS-resident cells, including astrocytes, microglia and neurons, secrete membranebound nanovesicles called exosomes under normal and pathological conditions [11]. In a study evaluating prion diseases, abnormally folded prion aggregates were found to associate with neuronal exosomes and infect both neuronal and non-neuronal cells without the need for direct cell-to-cell contact [12]. It was tempting to speculate that the factor(s) secreted from ER stressed cells were extracellular vesicles containing a heterogeneous species of RNA, protein or lipid that could induce ER stress in unstressed cell types. However, our MP isolation experiments demonstrated that both exosomes and other microvescles secreted by ER stressed astrocytes do not upregulate UPR markers in recipient astrocytes (Figure 5A). In parallel, it doesn’t seem that MPs secreted from cancer cells are responsible for triggering both ER stress and proinflammatory 
responses in receiver myeloid cells [13]. Treating ER stressed ACM with proteinase K did not rescue receiver cells from ER stress, suggesting that the stress molecule(s) is not a protein. However, we cannot exclude the possibility that it may exist in a proteinase K-resistant form, as disease-associated prion proteins do [14]. To add to the characterization of this stress factor(s), it appears that it cannot be inactivated by heat [15].

Identifying the soluble stress molecule(s) secreted by ER stressed astrocytes will be essential in order to better understand the molecular mechanisms involved in the cell-extrinsic regulatory function of the UPR. Based on our findings, transmissible ER stress does not appear to require cell-to-cell contact, thus supporting the notion that ER stress transmission is mediated by a stressinduced soluble molecule(s) [16]. While ER stress in other cell types has been shown to trigger the secretion of ER stress-inducing molecules, the identity of this factor(s) still remains elusive $[13,15,16]$. It is important to consider that this mediator(s) may not be a conventional DAMP, but rather an intracellular constituents released from the cell in an effort to alleviate ER stress. The secretion of products from the cell could be the result of an autophagy-dependent unconventional secretion pathway that is induced during cellular stress. The UPR is a well-known trigger of autophagosome formation, and the secretion of alarmins through this non-canonical autophagy pathway has been shown to serve different extracellular functions $[17,18]$. These secretory byproducts may, in turn, promote ER stress in neighboring cells. Nevertheless, this is purely speculation.

\subsection{Overall Conclusions}

To summarize, other studies investigating transmissible ER stress between mammalian cells discuss its potential role in disease progression. As represented in Figure 6, we propose that ER stressed astrocytes are able to confer resistance against upcoming ER stress-inducing insults to 
neurons by promoting the low-level activation of the UPR. In doing so, the pro-survival signals associated with the ER stress response are engaged (i.e. increased expression of molecular chaperones), thus enhancing the protein folding capacity of the cell. Nevertheless, chronic exposure to the uncharacterized stress factor(s) secreted by activated astrocytes induces unresolvable ER stress, which favors the initiation of UPR-dependent apoptosis. Therefore, the release of both inflammatory mediators (i.e. cytokines and ROS) and the ER stress-inducing factor(s) by dysfunctional astrocytes could contribute to the cell-nonautonomous mechanisms that drive the neurotoxic events observed in many neurodegenerative disorders.

These findings provide insight into the cell-extrinsic influence of the UPR on cells of the CNS. Because persistent ER stress generated during neuropathology turns the UPR into a pathological factor, understanding the molecular mechanisms underlying the cell-extrinsic functions of the UPR would present novel therapeutic opportunities to treat neurodegenerative diseases.

\subsection{Future Direction}

We hope to examine the relevance of our in vitro findings in a murine in vivo model. Currently, we are collaborating with Dr. Brain Popko and his laboratory at the University of Chicago to elucidate whether ER stress is transmissible within the CNS. We are taking advantage of the Jimpy mouse model to understand if ER stressed oligodendrocytes transmit ER stress to other cell types. Jimpy mice possess a mutation in the gene encoding the transmembrane protein proteolipid protein (PLP) that makes the protein susceptible to misfolding, thus leading to ER stress. Immunohistochemistry will enable us to visualize whether ER stress is being generated in nonoligodendrocyte cell types (i.e. astrocytes, microglia, and neurons).

\subsection{Potential Problems and their Solution}


PLP is vital for maintaining the structural integrity of the myelin sheath that insulates neuronal axons in the CNS. By mutating this protein we may compromise neuronal function if PLP is not properly expressed, which may lead to confounding results. Nevertheless, Klugmann et al. purposed that myelin produced by murine PLP-null oligodendrocytes is capable of being stably compacted around axons for $>1 \mathrm{y}$, and that the disease phenotype associated with jimpy mice is dependent on the toxic effects of misfolded PLP on oligodendrocytes [19]. Therefore, analysis of jimpy mice must be carried out before it is expected that the myelin architecture becomes unstable ( $<1$ y postnatal). To further support that ER stress generated in the oligodendrocytes can initiate ER stress transmission in vivo, we will attempt to recapitulate our in vitro findings using primary murine oligodendrocytes, if we indeed observe ER stress markers in both oligodendrocytes and other CNS-resident cell types following immunohistochemical staining. 


\subsection{References}

1. Mollereau B, Manie S, Napoletano F: Getting the better of ER stress. J Cell Commun Signal 2014, 8(4):311-321.

2. Taylor RC, Dillin A: XBP-1 is a cell-nonautonomous regulator of stress resistance and longevity. Cell 2013, 153(7):1435-1447.

3. Jones KT, Sharpe GR: Thapsigargin raises intracellular free calcium levels in human keratinocytes and inhibits the coordinated expression of differentiation markers. Exp Cell Res 1994, 210(1):71-76.

4. Minematsu H, Shin MJ, Celil Aydemir AB, Kim KO, Nizami SA, Chung GJ, Lee FY: Nuclear presence of nuclear factor of activated T cells (NFAT) c3 and c4 is required for Toll-like receptor-activated innate inflammatory response of monocytes/macrophages. Cell Signal 2011, 23(11):1785-1793.

5. Zhang K, Kaufman RJ: From endoplasmic-reticulum stress to the inflammatory response. Nature 2008, 454(7203):455-462.

6. Görlach A, Klappa P, Kietzmann T: The endoplasmic reticulum: folding, calcium homeostasis, signaling, and redox control. Antioxid Redox Signal 2006, 8(9-10):13911418.

7. Demuro A, Parker I: Cytotoxicity of intracellular a 342 amyloid oligomers involves Ca2+ release from the endoplasmic reticulum by stimulated production of inositol trisphosphate. J Neurosci 2013, 33(9):3824-3833.

8. Mekahli D, Bultynck G, Parys JB, De Smedt H, Missiaen L: Endoplasmic-reticulum calcium depletion and disease. Cold Spring Harb Perspect Biol 2011, 3(6).

9. $\quad$ Li G, Mongillo M, Chin K-T, Harding H, Ron D, Marks AR, Tabas I: Role of ERO1alpha-mediated stimulation of inositol 1,4,5-triphosphate receptor activity in endoplasmic reticulum stress-induced apoptosis. J Cell Biol 2009, 186(6):783-792.

10. Cao SS, Kaufman RJ: Endoplasmic reticulum stress and oxidative stress in cell fate decision and human disease. Antioxid Redox Signal 2014, 21(3):396-413.

11. Gupta A, Pulliam L: Exosomes as mediators of neuroinflammation. $J$ Neuroinflammation 2014, 11:68.

12. Fevrier B, Vilette D, Archer F, Loew D, Faigle W, Vidal M, Laude H, Raposo G: Cells release prions in association with exosomes. Proc Natl Acad Sci U S A 2004, 101(26):9683-9688.

13. Zanetti M, Rodvold JJ, Mahadevan NR: The evolving paradigm of cellnonautonomous UPR-based regulation of immunity by cancer cells. Oncogene 2016, 35(3):269-278.

14. Saunders GC, Horigan V, Tout AC, Windl O: Identification of a proteinase K resistant protein for use as an internal positive control marker in PrP Western blotting. Res Vet Sci 2007, 83(2):157-164.

15. Mahadevan NR, Rodvold J, Sepulveda H, Rossi S, Drew AF, Zanetti M: Transmission of endoplasmic reticulum stress and pro-inflammation from tumor cells to myeloid cells. Proc Natl Acad Sci U S A 2011, 108(16):6561-6566.

16. Zhang H, Yue Y, Sun T, Wu X, Xiong S: Transmissible endoplasmic reticulum stress from myocardiocytes to macrophages is pivotal for the pathogenesis of CVB3induced viral myocarditis. Sci Rep 2017, 7:42162. 
17. Ogata M, Hino S, Saito A, Morikawa K, Kondo S, Kanemoto S, Murakami T, Taniguchi $\mathrm{M}$, Tanii I, Yoshinaga $\mathrm{K}$ et al: Autophagy is activated for cell survival after endoplasmic reticulum stress. Mol Cell Biol 2006, 26(24):9220-9231.

18. Deretic V, Jiang S, Dupont N: Autophagy intersections with conventional and unconventional secretion in tissue development, remodeling and inflammation. Trends Cell Biol 2012, 22(8):397-406.

19. Klugmann M, Schwab MH, Puhlhofer A, Schneider A, Zimmermann F, Griffiths IR, Nave KA: Assembly of CNS myelin in the absence of proteolipid protein. Neuron 1997, 18(1):59-70. 